\title{
Tracking Control for Mobile Robots Considering the Dynamics of All Their Subsystems: Experimental Implementation
}

\author{
José Rafael García-Sánchez, ${ }^{1}$ Ramón Silva-Ortigoza, ${ }^{1}$ Salvador Tavera-Mosqueda, ${ }^{1}$ \\ Celso Márquez-Sánchez, ${ }^{1}$ Victor Manuel Hernández-Guzmán, ${ }^{2}$ Mayra Antonio-Cruz, ${ }^{1}$ \\ Gilberto Silva-Ortigoza, ${ }^{3}$ and Hind Taud ${ }^{1}$ \\ ${ }^{1}$ Área de Mecatrónica, CIDETEC, Instituto Politécnico Nacional, Unidad Profesional Adolfo López Mateos, \\ 07700 Ciudad de México, Mexico \\ ${ }^{2}$ Facultad de Ingeniería, Universidad Autónoma de Querétaro, 76150 Querétaro, QRO, Mexico \\ ${ }^{3}$ Facultad de Ciencias Físico Matemáticas, Benemérita Universidad Autónoma de Puebla, 72570 Puebla, PUE, Mexico \\ Correspondence should be addressed to Ramón Silva-Ortigoza; rsilvao@ipn.mx
}

Received 20 June 2017; Revised 2 September 2017; Accepted 19 September 2017; Published 7 December 2017

Academic Editor: Jinde Cao

Copyright (c) 2017 José Rafael García-Sánchez et al. This is an open access article distributed under the Creative Commons Attribution License, which permits unrestricted use, distribution, and reproduction in any medium, provided the original work is properly cited.

\begin{abstract}
The trajectory tracking task in a wheeled mobile robot (WMR) is solved by proposing a three-level hierarchical controller that considers the mathematical model of the mechanical structure (differential drive WMR), actuators (DC motors), and power stage (DC/DC Buck power converters). The highest hierarchical level is a kinematic control for the mechanical structure; the medium level includes two controllers based on differential flatness for the actuators; and the lowest hierarchical level consists of two average controllers also based on differential flatness for the power stage. In order to experimentally validate the feasibility of the proposed control scheme, the hierarchical controller is implemented via a $\Sigma$ - $\Delta$-modulator in a differential drive WMR prototype that we have built. Such an implementation is achieved by using MATLAB-Simulink and the real-time interface ControlDesk together with a DS1104 board. The experimental results show the effectiveness and robustness of the proposed control scheme.
\end{abstract}

\section{Introduction}

In recent years, wheeled mobile robots (WMRs) have been widely studied [1-3]. As a matter of fact, diverse applications of WMRs have been reported in many fields like handling explosives or radioactive materials/waste, planetary and maritime exploration, mining and petrochemical industry, medicine, agriculture, home, and entertainment, among others [4-7]. On one hand, control of WMRs is not an easy task since their models are nonlinear and are subject to nonholonomic constraints $[8,9]$. Despite these difficulties, significant advances have been achieved in the design of controllers solving several problems associated with a WMR: regulation, path following, obstacle avoidance, and trajectory tracking.

Nevertheless, to the best of the authors' knowledge, any of the control schemes reported with experiments until now have not taken into account the full dynamics of the three subsystems composing, in general, a WMR, that is, (a) mechanical structure, (b) actuators, and (c) power stage. This is because most controllers solving the aforementioned problems have been designed by only taking into account the kinematic/dynamic model of the WMR mechanical structure and just few others have been designed by taking into account the actuators mathematical model. This means that importance of the power stage has been neglected. However, it is stated in [10] that taking into account the power stage 
dynamics in the design of control algorithms for mechatronic systems leads to important improvements. Moreover, not only dynamics of the power stage but also, if required, dynamics associated with the electric power generation should be considered. This is, by itself, an important current research topic [11-19].

One of the main reasons why dynamics associated with power stage and electric power generation are not considered when designing controllers for WMRs is that the resulting mathematical model becomes more complex and, hence, design of the control algorithm also becomes more complex. However, consideration of dynamics associated with these subsystems could lead to new research areas where the power electronics would play an important role with regard to the storage, distribution, and transformation of electrical energy [20-28]. Some approximations in this direction are presented in $[29,30]$, where dynamics associated with actuators, power stage, and electric power generation are considered in mechatronic systems.

The remainder of this paper is organized as follows. Previous works on trajectory tracking for WMRs are reviewed in Section 2, while a discussion on such a literature and contribution of the present paper are given in Section 3. In Section 4, design of a three-level hierarchical controller that solves the trajectory tracking task in a WMR is presented. Some experimental results obtained when controlling a WMR prototype that we have built are shown in Section 5 . Finally, conclusions are given in Section 6.

\section{Literature Review}

With the purpose of underlining contribution of the present paper, an exhaustive review of the more relevant literature on trajectory tracking in differential drive WMRs is presented below. Two main approaches related to the mechanical structure have been proposed: (i) design based on the WMR kinematic model and (ii) design based on the WMR dynamic model. Thus, the state-of-the-art review is based on whether or not dynamics associated with the other two WMR subsystems, that is, the actuators and the power stage, are taken into account.

2.1. Considering Only the Mechanical Structure. This subsection describes previous works related to the trajectory tracking task, where the mathematical model, either kinematic or dynamic, of only the mechanical structure of a differential drive WMR is employed.

2.1.1. Kinematic Model. Papers that take into account the kinematic model of a differential drive WMR when designing control algorithms are considered here. Kanayama et al. [31] proposed a stable tracking control strategy to determine the linear and rotational velocities of a vehicle. They have also shown through numerical simulations that their controller is still effective when there are small disturbances. Samson and Ait-Abderrahim [32] introduced a feedback controller designed on the basis of a virtual reference for position and orientation. Murray and Sastry [33] reported a methodology to represent a WMR in chained form. They have also succeeded to track a preestablished trajectory by using sinusoids as control inputs. A robust controller based on sliding modes was proposed by Chacal and Sira-Ramírez [34], where the system differential flatness property is used and stochastic perturbation signals are considered. Walsh et al. [35] designed an exponentially stable control law. Jiang and Nijmeijer [36] introduced two controllers based on backstepping, a local one and a global one. Both controllers achieve exponential convergence. Kim and Oh [37] developed a modified inputoutput linearization controller for nonsquare systems, where the three state variables are considered as outputs. Jiang and Nijmeijer [38] focused on a recursive technique to solve the trajectory tracking and path following tasks when the system is represented in a chained form. This was carried out through a coordinate transformation. Dixon et al. [39] implemented a differentiable kinematic control law that uses a damped dynamic oscillator, which achieves the exponential convergence of the tracking and regulation errors to a neighborhood of the origin. Another work introduced by Dixon et al. [40] dealt with a differentiable kinematic control law that allows simultaneously solving the trajectory tracking and regulation problems, exponentially for the first one and asymptotically for the second one. Additionally, Dixon et al. [41] elaborated a variable structure-like tracking controller that is robust under parametric uncertainty, also with exponential convergence of the tracking and regulation errors to the origin. In [42], Lee et al. solved the trajectory tracking and regulation problems via a backstepping control. By using polar coordinates, Chwa [43] designed a pair of discontinuous controllers to asymptotically stabilize the trajectory tracking errors in position and in the heading direction. Thus, the trajectory tracking and stabilization problems were solved. Klančar and Škrjanc [44] proposed a model-predictive trajectory tracking control, where the linearized tracking error dynamics is used to predict the behavior of a WMR. Another solution of the trajectory tracking task was carried out by Tsai et al. [45], where a robust visual tracking control to track a dynamic moving object was considered. Lee et al. [46] carried out a sliding mode control by using an RFID sensor space to estimate the position of a WMR. Recently, Scaglia et al. [47] suggested a linear interpolation based methodology to design control algorithms. It is assumed that the evolution of the system can be approximated by a linear interpolation. Hence, the tracking errors can be reduced by decreasing the sampling time. Cheng et al. [48] suggested a feedback control law via Lyapunov's direct method and backstepping, achieving global asymptotic stability. Lastly, Chwa [49] studied a fuzzy adaptive tracking controller by considering the slippage between the wheels and the surface. Other relevant papers concerning the controller design by using only the kinematic model of the mechanical structure are [50-59].

2.1.2. Dynamic Model. One of the first papers where the dynamic model of a WMR was taken into account for the design of a controller was by d'Andréa-Novel et al. [60], who obtained the WMR dynamic model through the EulerLagrange formulation. In addition, they introduced a control law based on static state feedback. Fierro and Lewis [61] 
elaborated a kinematic/torque control law using backstepping to solve the trajectory tracking, path following, and stabilization problems. Yang and Kim [62] suggested a sliding mode controller, which is robust to bounded external disturbances. Dong et al. [63] developed an adaptive robust controller that does not require exactly knowing the WMR physical parameters. Dixon et al. [64] dealt with a visual servoing controller that adapts to the parametric uncertainty associated with the camera and with the mechanical parameters of the WMR dynamic model. Likewise, Pourboghrat and Karlsson [65] elaborated a robust adaptive controller to solve the trajectory tracking and stabilization problems. Dong and Kuhnert [66] focused on the design of an adaptive neural network control that is robust to parametric uncertainty. Chen et al. [67] proposed a kinematic control to generate the desired velocity profiles for the wheels. They also formulated an adaptive sliding mode controller that allows the real velocities to reach the desired ones. Solea et al. [68] presented a robust sliding mode controller when there are external disturbances and parametric uncertainty in the WMR. Recently, Cao et al. [69] developed an adaptive kinematic controller (based on the backstepping method) and a dynamic adaptive controller. The latter allows reaching the desired velocity profiles imposed by the former. Shojaei et al. [70] designed a control algorithm, robust under parametric and nonparametric uncertainty, which combines an inverse dynamics control and an adaptive robust PID control. Finally, other contributions that employ the dynamic model only of the WMR mechanical structure in the control design can be found in [71-80].

2.2. Considering the Mechanical Structure and Actuators. It has not been common to take into account the dynamics of the actuators in research related to WMRs. However, it is important to highlight that the exclusion of this dynamics can cause degradation in the performance of a robot [81] and even can produce system instability [82-84]. Few papers have incorporated such dynamics into the control algorithms when the kinematic or dynamic model of the WMR is considered. This subsection reviews the research that has employed the mathematical model of both the mechanical structure and the actuators in the trajectory tracking control design for differential drive WMRs.

2.2.1. Kinematic Model. By considering both the mechanical structure and the actuators, Espinosa et al. [85] designed an adaptive optimal controller in the drive control loop and an optimal-fuzzy control for the trajectory tracking task for a wheelchair when there are obstacles in the workspace. SilvaOrtigoza et al. [86] designed a two-stage controller where the first stage corresponds to a control based on input-output linearization for the mechanical structure and the second stage refers to a controller based on differential flatness for the actuators. Recently, Zuo et al. [87] described a control strategy that integrates a kinematic control and an adaptive wavelet neural network, which is robust to disturbances. Lastly, Silva-Ortigoza et al. [88] proposed a robust hierarchical controller where the high-level control is based on inputoutput linearization for the mechanical structure and the lowlevel control is based on a PI control for the actuators.

2.2.2. Dynamic Model. Taking into account both the dynamic model of the mechanical structure and the mathematical model of the actuators during the control design stage for the WMR is not easy, since control design becomes more complex. However, it allows designing controllers that solve the trajectory tracking problem more effectively. This can be observed when the WMR is moving at high speeds or when its mass is variable [89]. Motivated by these facts, Anupoju et al. [90] designed three adaptive controllers, the first one for the kinematic model of the mechanical structure, the second one for the dynamic model of that same mechanical structure, and the third one for the actuators. Das and Kar [91] formulated an adaptive fuzzy logic-based controller. Hou et al. [92] proposed a robust adaptive controller via backstepping and a fuzzy logic approach. More recently, Luo et al. [93] elaborated an adaptive neural network dynamic surface controller based on a disturbance observer, where uncertain parameters were taken into account. Lastly, other contributions that take into account the dynamic model of the mechanical structure and the dynamics of the actuators in the control design are reported in [94-103].

2.3. Considering the Mechanical Structure, Actuators, and Power Stage. Few controllers have considered the mathematical models of the three subsystems that compose a WMR. In such controllers, only the kinematic model of the WMR has been used.

2.3.1. Kinematic Model. Ortigoza et al. in [104] presented a trajectory tracking controller by considering an input-output linearization-based controller for the mechanical structure, a controller based on differential flatness for the actuators, and a sliding mode plus PI controller for the power stage. In [105], Sánchez et al. proposed a kinematic controller for the WMR, a controller based on differential flatness for the actuators, and a differential flatness-based controller for the power stage. Controllers reported in $[104,105]$ were tested only via numerical simulations.

\section{Discussion and Contribution}

After carrying out the review of the literature associated with design of controllers for the trajectory tracking task in differential drive WMRs, it was found that, generally, this task has been solved in three directions: (a) by only using the kinematic or dynamic model of the mechanical structure [31-80], (b) by employing the kinematic/dynamic model of the mechanical structure along with the dynamics of the actuators [85-103], and (c) by considering the kinematic model of the mechanical structure along with the dynamics of the actuators and power stage $[104,105]$. In the last direction, contributions that have carried out interesting efforts are [106-114]. However, those papers only focus on the design of the power stage without considering the other dynamics. 
Motivated by the aforementioned ideas, the hierarchical control approach in mobile robotics (see $[86,104,105,115]$ ), and use of DC/DC converter-DC motor systems (see [116, 117]), the purpose of the present paper is threefold. First, it aims, to introduce a three-level hierarchical controller that considers dynamics of the three subsystems that compose a WMR to solve, in a more complete way, the trajectory tracking task. Second, it aims, to experimentally validate the proposed controller by implementing it in a WMR prototype that we have built, where the experimental results show the effectiveness and robustness of the designed hierarchical controller. Third, it aims, to experimentally compare to results associated with a controller that neglects dynamics of the power stage. After an assessment of the results, it is observed that the performance of the WMR with the hierarchical controller is better than, or at least similar to, the one achieved with the control that neglects the dynamics of the power stage.

\section{Hierarchical Trajectory Tracking Control via $\Sigma-\Delta$-Modulator Considering the Dynamics of All the WMR Subsystems}

A hierarchical trajectory tracking controller for a differential drive WMR is presented in this section, which is designed by considering dynamics of all of the subsystems that integrate a WMR. The system under study is shown in Figure 1, where the three subsystems can be seen, that is, mechanical structure (differential drive WMR), actuators (DC motors), and power stage (DC/DC Buck power converters). In such a figure, and in the remainder of this paper, the parameters, components, and variables associated with the right Buck converter-DC motor and left Buck converter-DC motor are distinguished by the subscripts $r$ and $l$, respectively. The design of the hierarchical controller is carried out as follows:

(1) At the highest hierarchical level, a kinematic controller for the mechanical structure delivers the desired DC motor angular velocities $\omega_{r}$ and $\omega_{l}$. If velocities of wheels reach these values, then the WMR tracks the desired trajectory; that is, $(x, y, \varphi) \rightarrow$ $\left(x^{*}, y^{*}, \varphi^{*}\right)$.

(2) At the medium level, two flatness-based controllers deliver $\vartheta_{r}$ and $\vartheta_{l}$, the desired voltage profiles that the Buck converters output voltages have to track. If these desired voltages are reached, then the angular velocities of the DC motors track the desired angular velocity profiles; that is, $\left(\omega_{r}, \omega_{l}\right) \rightarrow\left(\omega_{r}, \omega_{l}\right)$.

(3) At the lowest level, two flatness-based average controllers deliver $u_{\mathrm{av}_{r}}$ and $u_{\mathrm{av}_{l}}$ which ensure that the Buck converters output voltages track the desired voltage profiles; that is, $\left(v_{r}, v_{l}\right) \rightarrow\left(\vartheta_{r}, \vartheta_{l}\right)$.

In order to accomplish the trajectory tracking task for the WMR, the controllers designed in (1)-(3) are interconnected using a hierarchical approach. The switched implementation of the resulting controller is performed at the Buck converters by using the $\Sigma-\Delta$-modulator [118].

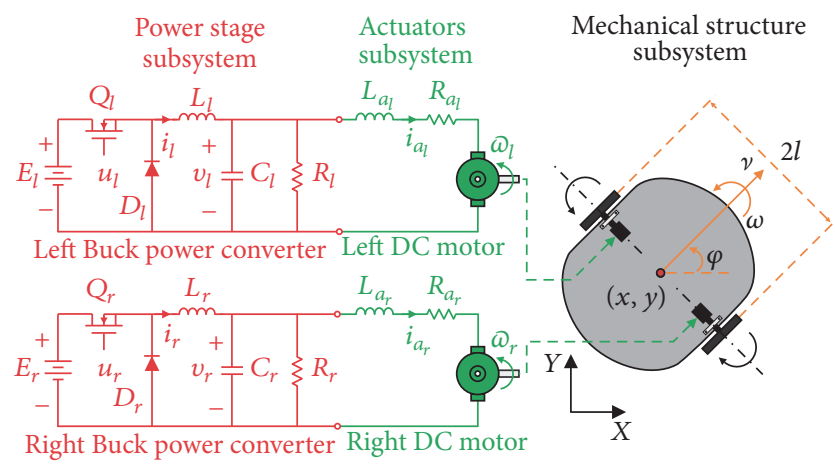

FIGURE 1: WMR complete system.

4.1. Control at the Highest Hierarchical Level: Mechanical Structure. In this subsection, a kinematic controller that solves the trajectory tracking task in a WMR is presented.

The kinematic model of a differential drive WMR, which moves without slipping on the $X Y$ plane, is given by [119]

$$
\begin{aligned}
& \dot{x}=v \cos \varphi, \\
& \dot{y}=v \sin \varphi, \\
& \dot{\varphi}=\omega,
\end{aligned}
$$

with the inputs

$$
\left(\begin{array}{c}
v \\
\omega
\end{array}\right)=\left(\begin{array}{cc}
\frac{r}{2} & \frac{r}{2} \\
\frac{r}{2 l} & -\frac{r}{2 l}
\end{array}\right)\left(\begin{array}{l}
\omega_{r} \\
\omega_{l}
\end{array}\right)
$$

where $(x, y)$ is the position of the midpoint of the axis which joins the wheels and $\varphi$ is the orientation of the WMR. Also, $r$ is radius of the driving wheels and $2 l$ is distance between them, while $\omega_{r}$ and $\omega_{1}$ are the right and left angular velocities of the wheels, respectively. Lastly, $v$ is the straight line velocity and $\omega$ is the angular velocity, both of the WMR (see Figure 1). In these equations, and in the remainder of this paper, the derivative with respect to time $t$ will be denoted by a "dot" or by $d / d t$.

The control objective is tracking of the following reference robot:

$$
\begin{aligned}
& \dot{x}^{*}=v^{*} \cos \varphi^{*}, \\
& \dot{y}^{*}=v^{*} \sin \varphi^{*}, \\
& \dot{\varphi}^{*}=\omega^{*},
\end{aligned}
$$

where $\left(x^{*}, y^{*}\right)$ and $\varphi^{*}$ represent the pose and orientation, respectively, of the reference robot, whereas $v^{*}$ and $\omega^{*}$ are its reference inputs. Thus, in accordance with [98], the following error signals are defined:

$$
\left(\begin{array}{l}
e_{1} \\
e_{2} \\
e_{3}
\end{array}\right)=\left(\begin{array}{ccc}
K_{2} \cos \varphi & K_{2} \sin \varphi & 0 \\
-K_{2} \sin \varphi & K_{2} \cos \varphi & \alpha \\
0 & 0 & 1
\end{array}\right)\left(\begin{array}{l}
x^{*}-x \\
y^{*}-y \\
\varphi^{*}-\varphi
\end{array}\right) \text {, }
$$


with $K_{2}$ and $\alpha$ being positive constants. In (4), the matrix is globally nonsingular because its determinant is equal to $K_{2}^{2}$. The time derivative of (4) is given as

$$
\begin{aligned}
\left(\begin{array}{c}
\dot{e}_{1} \\
\dot{e}_{2} \\
\dot{e}_{3}
\end{array}\right)= & \left(\begin{array}{cc}
-K_{2} & e_{2}-\alpha e_{3} \\
0 & -e_{1}-\alpha \\
0 & -1
\end{array}\right)\left(\begin{array}{l}
v \\
\omega
\end{array}\right) \\
& +\left(\begin{array}{c}
\nu^{*} K_{2} \cos e_{3} \\
K_{2} \nu^{*} \sin e_{3}+\alpha \omega^{*} \\
\omega^{*}
\end{array}\right),
\end{aligned}
$$

where (1) and (3) have been used. The following control inputs have been retaken from [71]:

$$
\begin{aligned}
& v=v^{*} \cos e_{3}+K_{1} e_{1}, \\
& \omega=\omega^{*}+v^{*} K_{2} e_{2}+K_{3} \sin e_{3},
\end{aligned}
$$

with $K_{1}$ and $K_{3}$ being positive constants. In [98], the following positive function was defined:

$$
V\left(e_{1}, e_{2}, e_{3}\right)=\frac{1}{2} e_{1}^{2}+\frac{1}{2} e_{2}^{2}+\left(1-\cos e_{3}\right) .
$$

Through the analysis of its time derivative, $\dot{V}$, along trajectories (5), when (6) are considered as control inputs, it was shown that the error dynamics (5) is asymptotically stable; that is, $\left(e_{1}, e_{2}, e_{3}\right)=(0,0,0)$, since matrix in (4) is nonsingular. This fact implies that system (1) in closed loop with (6) achieves that $(x, y, \varphi) \rightarrow\left(x^{*}, y^{*}, \varphi^{*}\right)$ when $t \rightarrow \infty$. Likewise, according to the stability analysis carried out in [98], it was shown that $\alpha=1 / K_{3}$ and $\nu^{*}$ must be greater than 0 .

Lastly, by substituting (6) in (2), after some mathematical manipulation, the controls are transformed into the right and left angular velocities to be used as inputs. That is,

$$
\begin{aligned}
& \omega_{r}=\frac{v^{*}\left(\cos e_{3}+l K_{2} e_{2}\right)+l\left(\omega^{*}+K_{3} \sin e_{3}\right)+K_{1} e_{1}}{r}, \\
& \omega_{l}=\frac{v^{*}\left(\cos e_{3}-l K_{2} e_{2}\right)-l\left(\omega^{*}+K_{3} \sin e_{3}\right)+K_{1} e_{1}}{r} .
\end{aligned}
$$

4.2. Control at the Medium Level: Actuators. The objective of this subsection is to design a controller ensuring that the actual angular velocities of the DC motors $\left(\omega_{r}, \omega_{l}\right)$ track the desired angular velocity profiles imposed by the WMR kinematic control $\left(\omega_{r}, \omega_{l}\right)$; that is, $\left(\omega_{r}, \omega_{l}\right) \rightarrow\left(\omega_{r}, \omega_{l}\right)$.

The mathematical model of a DC motor expressed in terms of the angular velocity [119], $\omega$, is given by

$$
\begin{aligned}
L_{a} \frac{d i_{a}}{d t} & =\vartheta-R_{a} i_{a}-k_{e} \omega, \\
J \frac{d \omega}{d t} & =-b \omega+k_{m} i_{a},
\end{aligned}
$$

where $\vartheta$ is the input voltage of the motor, $i_{a}$ is the armature current, $k_{e}$ is the counterelectromotive force constant, $k_{m}$ is the motor torque constant, $L_{a}$ is the armature inductance, $R_{a}$ is the armature resistance, $J$ is the moment of inertia of the rotor and motor load, and $b$ is the viscous friction coefficient of the motor.

Since the aforementioned parameters are required for control design and manufacturer does not provide them, in this paper such parameters are obtained via the experimental characterization of the DC motor. For such an aim, a firstorder approximation of (10) is considered by assuming that armature inductance may be neglected [120]. That is,

$$
\frac{d \omega}{d t}=-\mu \omega+\gamma \vartheta
$$

where

$$
\begin{aligned}
\mu & =\frac{1}{\tau}, \\
\gamma & =\frac{K}{\tau}, \\
\tau & =\frac{J R_{a}}{b R_{a}+k_{e} k_{m}}, \\
K & =\frac{k_{m}}{b R_{a}+k_{e} k_{m}} .
\end{aligned}
$$

In order to get the numerical values of the parameters $\tau$ and $K$, an experimental characterization must be done. The corresponding values of $\tau$ and $K$ associated with the right motor characterization are

$$
\begin{aligned}
\tau_{r} & =98 \times 10^{-3}, \\
K_{r} & =540 \times 10^{-3},
\end{aligned}
$$

and for the left motor

$$
\begin{aligned}
\tau_{l} & =98 \times 10^{-3}, \\
K_{l} & =590 \times 10^{-3} .
\end{aligned}
$$

In this manner, using (11), (12), (14), and (15), the first-order dynamic models of the DC motors are given by

$$
\frac{d \omega_{r}}{d t}=-10.2 \omega_{r}+5.5 \vartheta_{r}
$$

for the right motor and

$$
\frac{d \omega_{l}}{d t}=-10.2 \omega_{l}+6 \vartheta_{l}
$$

for the left motor.

On the other hand, with the intention to achieve $\left(\omega_{r}, \omega_{l}\right) \rightarrow\left(\omega_{r}, \omega_{l}\right)$, a differential flatness-based control [119, $121,122]$ is proposed for the first-order linear system (11). To this end, the dynamics (11) is rewritten in terms of the flat output $F_{1}=\omega$, as

$$
\vartheta=\frac{\dot{F}_{1}+\mu F_{1}}{\gamma} \text {. }
$$


If the control input $\vartheta$ is chosen as

$$
\vartheta=\frac{\delta+\mu F_{1}}{\gamma}
$$

and it is replaced in (18), then the tracking problem related to the angular velocity of the DC motor is reduced to control the following system:

$$
\dot{F}_{1}=\delta \text {, }
$$

where $\delta$ is an auxiliary control. In order to ensure that $F_{1} \rightarrow$ $F_{1}^{*}$ when $t \rightarrow \infty$, a proper selection for $\delta$ is

$$
\delta=\dot{F}_{1}^{*}-k_{p}\left(F_{1}-F_{1}^{*}\right)-k_{i} \int_{0}^{t}\left(F_{1}-F_{1}^{*}\right) d \sigma,
$$

with $F_{1}^{*}$ being the desired angular velocity, that is, either $\omega_{r}$ or $\omega_{l}$ for the right or the left motor, respectively, and $\left(k_{p}, k_{i}\right)$ positive constants. Once (21) is replaced in (20), the tracking error is defined as $e_{m}=F_{1}-F_{1}^{*}$, and the derivative with respect to time of the resulting expression is calculated. Then, the following tracking error dynamics is obtained:

$$
\ddot{e}_{m}+k_{p} \dot{e}_{m}+k_{i} e_{m}=0
$$

whose characteristic polynomial is

$$
p_{c_{1}}(s)=s^{2}+k_{p} s+k_{i}
$$

By equating (23) with a Hurwitz polynomial defined by

$$
p_{d_{1}}(s)=s^{2}+2 \xi_{1} \omega_{n_{1}} s+\omega_{n_{1}}^{2},
$$

where $\left(\xi_{1}, \omega_{n_{1}}\right)>0$, not only is $F_{1} \rightarrow F_{1}^{*}$ achieved, but also the gains $k_{p}$ and $k_{i}$ are found. That is,

$$
\begin{aligned}
& k_{p}=2 \xi_{1} \omega_{n_{1}}, \\
& k_{i}=\omega_{n_{1}}^{2} .
\end{aligned}
$$

4.3. Control at the Lowest Hierarchical Level: Power Stage. The purpose of this subsection is to propose a controller that allows the actual output voltages of the Buck converters $\left(v_{r}, v_{l}\right)$ to track the desired voltage profiles $\left(\vartheta_{r}, \vartheta_{l}\right)$ imposed by controllers of the DC motors; that is, $\left(v_{r}, v_{l}\right) \rightarrow\left(\vartheta_{r}, \vartheta_{l}\right)$.

According to [118], the average dynamics of a Buck converter are given as

$$
\begin{aligned}
L \frac{d i}{d t} & =-v+E u_{\mathrm{av}}, \\
C \frac{d v}{d t} & =i-\frac{v}{R},
\end{aligned}
$$

where $i$ is electric current through the inductor $L, v$ is the output voltage of the converter associated with the capacitor $C, R$ is the load resistance, and $E$ is voltage of the converter power supply. Variable $u_{\text {av }}$ represents the switch position, which is an average signal that satisfies $u_{\mathrm{av}} \in[0,1]$. It is important to mention that the switched model of the Buck converter is obtained when $u_{\mathrm{av}}$ is replaced by $u$ in (26), with $u$ being a signal that takes values in the discrete set $\{0,1\}$.

In order to design a differential flatness-based controller for the converter $[119,123-125]$, the dynamics (26) is represented in terms of the flat output $F_{2}=v$, as follows:

$$
u_{\mathrm{av}}=\frac{L C}{E} \ddot{F}_{2}+\frac{L}{R E} \dot{F}_{2}+\frac{1}{E} F_{2},
$$

with the suitable definition of $u_{\mathrm{av}}$, given by

$$
u_{\mathrm{av}}=\frac{L C}{E} \eta+\frac{L}{R E} \dot{F}_{2}+\frac{1}{E} F_{2} .
$$

After replacing (28) in (27), the tracking problem, associated with the output voltage of the Buck converter, is reduced to control the system given by

$$
\ddot{F}_{2}=\eta \text {. }
$$

In order to achieve that $F_{2} \rightarrow F_{2}^{*}$ when $t \rightarrow \infty$, with $F_{2}^{*}$ being the desired voltage profile at the converter output, that is, either $\vartheta_{r}$ or $\vartheta_{l}$ for the right or left Buck converters, respectively, a convenient proposal of $\eta$ is

$$
\begin{aligned}
\eta= & \ddot{F}_{2}^{*}-\beta_{2}\left(\dot{F}_{2}-\dot{F}_{2}^{*}\right)-\beta_{1}\left(F_{2}-F_{2}^{*}\right) \\
& -\beta_{0} \int_{0}^{t}\left(F_{2}-F_{2}^{*}\right) d \sigma .
\end{aligned}
$$

When (30) is substituted into (29) and after defining the tracking error as $e_{c}=F_{2}-F_{2}^{*}$, the following tracking error dynamics is obtained:

$$
\dddot{e}_{c}+\beta_{2} \ddot{e}_{c}+\beta_{1} \dot{e}_{c}+\beta_{0} e_{c}=0,
$$

whose characteristic polynomial is

$$
p_{c_{2}}(s)=s^{3}+\beta_{2} s^{2}+\beta_{1} s+\beta_{0},
$$

which is forced to be stable by equating it with a Hurwitz polynomial to achieve $F_{2} \rightarrow F_{2}^{*}$, defined by

$$
p_{d_{2}}(s)=\left(s+a_{2}\right)\left(s^{2}+2 \xi_{2} \omega_{n_{2}} s+\omega_{n_{2}}^{2}\right) \text {, }
$$

with $a_{2}>0, \xi_{2}>0$, and $\omega_{n_{2}}>0$. Hence, the gains $\beta_{2}, \beta_{1}$, and $\beta_{0}$ are determined by

$$
\begin{aligned}
& \beta_{2}=a_{2}+2 \xi_{2} \omega_{n_{2}}, \\
& \beta_{1}=2 \xi_{2} \omega_{n_{2}} a_{2}+\omega_{n_{2}}^{2}, \\
& \beta_{0}=a_{2} \omega_{n_{2}}^{2} .
\end{aligned}
$$

4.4. Hierarchical Tracking Control. In this subsection, controllers designed in Sections 4.1, 4.2, and 4.3 are integrated using a hierarchical approach (see $[86,104,105,115-117])$ to solve the trajectory tracking task for a differential drive WMR when dynamics associated with each one of subsystems composing the WMR are considered (see Figure 1).

Using the kinematic models associated with a differential drive WMR (1) and a reference robot (3), it was found that 
velocity profiles $\omega_{r}$ and $\omega_{l}$, ensuring $(x, y, \varphi) \rightarrow\left(x^{*}, y^{*}, \varphi^{*}\right)$, are given by (8) and (9), respectively. On the other hand, profiles of voltages $\vartheta_{r}$ and $\vartheta_{l}$ that applied to DC motors ensure $\left(\omega_{r}, \oplus_{l}\right) \rightarrow\left(\omega_{r}, \omega_{l}\right)$ are given, according to (19) and (21), as

$$
\begin{gathered}
\vartheta_{r}=\frac{\delta_{r}+\mu_{r} \varrho_{r}}{\gamma_{r}}, \\
\vartheta_{l}=\frac{\delta_{l}+\mu_{l} \varrho_{l}}{\gamma_{l}},
\end{gathered}
$$

with the auxiliary controls $\delta_{r}$ and $\delta_{l}$ defined by

$$
\begin{aligned}
& \delta_{r}=\dot{\omega}_{r}^{*}-k_{p_{r}}\left(\omega_{r}-\omega_{r}^{*}\right)-k_{i_{r}} \int_{0}^{t}\left(\omega_{r}-\omega_{r}^{*}\right) d \sigma, \\
& \delta_{l}=\dot{\omega}_{l}^{*}-k_{p_{l}}\left(\omega_{l}-\omega_{l}^{*}\right)-k_{i_{l}} \int_{0}^{t}\left(\omega_{l}-\omega_{l}^{*}\right) d \sigma,
\end{aligned}
$$

where

$$
\left(\omega_{r}^{*}, \omega_{l}^{*}\right)=\left(\omega_{r}, \omega_{l}\right) .
$$

Likewise, since each DC motor is driven by a Buck converter, it is found from (28) and (30) that the actual voltages at the converters outputs are ensured to converge to their desire profiles; that is, $\left(v_{r}, v_{l}\right) \rightarrow\left(\vartheta_{r}, \vartheta_{l}\right)$, if the converter transistors are commuted according to $u_{a v_{r}}$ and $u_{a v_{l}}$, which are given as

$$
\begin{aligned}
& u_{a v_{r}}=\frac{L_{r} C_{r}}{E_{r}} \eta_{r}+\frac{L_{r}}{R_{r} E_{r}} \dot{v}_{r}+\frac{1}{E_{r}} v_{r}, \\
& u_{a v_{l}}=\frac{L_{l} C_{l}}{E_{l}} \eta_{l}+\frac{L_{l}}{R_{l} E_{l}} \dot{v}_{l}+\frac{1}{E_{l}} v_{l},
\end{aligned}
$$

with the auxiliary controls $\eta_{r}$ and $\eta_{l}$ defined by

$$
\begin{aligned}
\eta_{r}= & \ddot{v}_{r}^{*}-\beta_{2_{r}}\left(\dot{v}_{r}-\dot{v}_{r}^{*}\right)-\beta_{1_{r}}\left(v_{r}-v_{r}^{*}\right) \\
& -\beta_{0_{r}} \int_{0}^{t}\left(v_{r}-v_{r}^{*}\right) d \sigma, \\
\eta_{l}= & \ddot{v}_{l}^{*}-\beta_{2_{l}}\left(\dot{v}_{l}-\dot{v}_{l}^{*}\right)-\beta_{1_{l}}\left(v_{l}-v_{l}^{*}\right) \\
& -\beta_{0_{l}} \int_{0}^{t}\left(v_{l}-v_{l}^{*}\right) d \sigma,
\end{aligned}
$$

where

$$
\left(v_{r}^{*}, v_{l}^{*}\right)=\left(\vartheta_{r}, \vartheta_{l}\right) .
$$

Finally, since controllers (40) and (41) have been designed on the basis of average models of the Buck converters, the corresponding switched implementations, $u_{r}$ and $u_{l}$, are achieved using a $\Sigma-\Delta$-modulator [118]. Hence, both signals $u_{r}$ and $u_{l}$ only take values in the discrete set $\{0,1\}$. Thus,

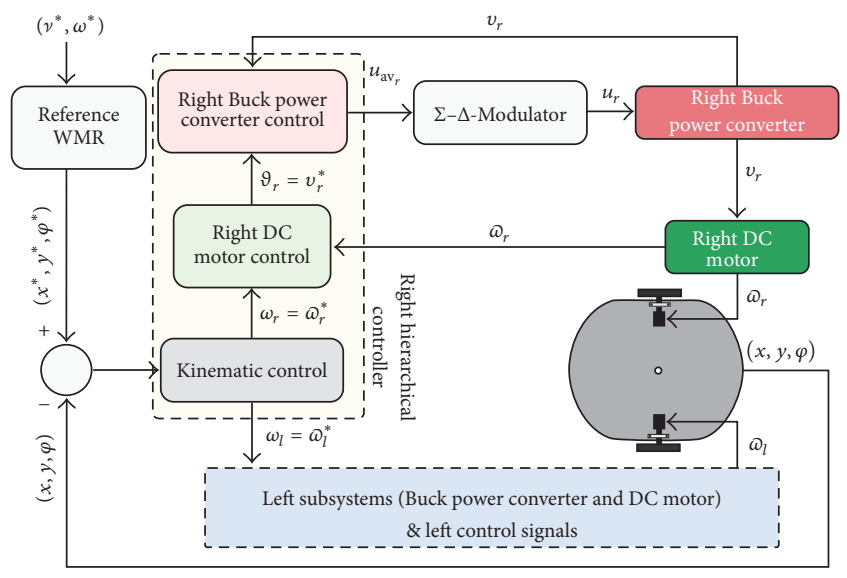

FIGURE 2: Block diagram of the hierarchical controller along with the WMR.

synthesis of the average controllers (40) and (41) via a $\Sigma-\Delta$ modulator is given as

$$
\begin{aligned}
& u_{r}=\frac{1}{2}\left[1+\operatorname{sign}\left(e_{r}\right)\right], \\
& \dot{e}_{r}=u_{a v_{r}}-u_{r}, \\
& u_{l}=\frac{1}{2}\left[1+\operatorname{sign}\left(e_{l}\right)\right], \\
& \dot{e}_{l}=u_{a v_{l}}-u_{l} .
\end{aligned}
$$

In summary, the switched controllers (45)-(46) ensure that $\left(v_{r}, v_{l}\right) \rightarrow\left(\vartheta_{r}, \vartheta_{l}\right)$, so that $\left(\oplus_{r}, \oplus_{l}\right) \rightarrow\left(\omega_{r}, \omega_{l}\right)$. In consequence, the control objective for the WMR is attained; that is, $(x, y, \varphi) \rightarrow\left(x^{*}, y^{*}, \varphi^{*}\right)$. The integration of the hierarchical controller is shown in the block diagram presented in Figure 2.

\section{Experimental Results}

In this section, some experiments are presented intended to evaluate performance achieved by the hierarchical controller that has been designed. Controller (8)-(9), (35)-(36), and (45)-(46) has been tested on the WMR prototype shown in Figure 3. This prototype has, as power stage, two DC/DC Buck power converters. Controller reported in [98] is also tested for comparison purposes. Since controller in [98] is designed without taking into account the power stage dynamics, another WMR prototype is employed, which possesses H-bridges instead of DC/DC Buck power converters. See Figure 4.

5.1. Experimental Results of the Hierarchical Controller. Implementation of the hierarchical controller was carried out in the differential drive WMR prototype shown in Figure 3, which was designed and built at the Mechatronics Laboratory of CIDETEC-IPN.

The WMR prototype shown in Figure 3 is $0.39 \mathrm{~m}$ in length, $0.36 \mathrm{~m}$ in width, and $0.35 \mathrm{~m}$ in height, and its total 


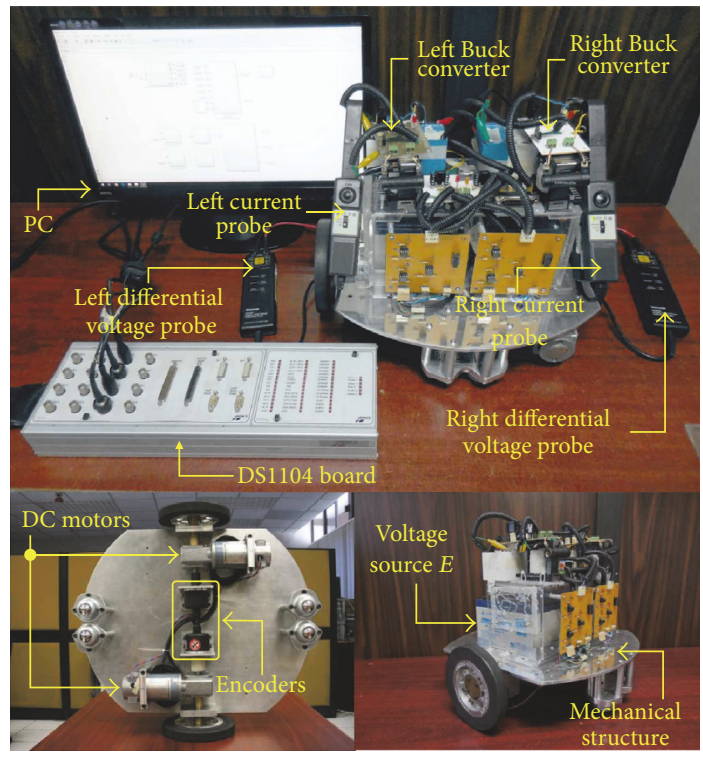

FIGURE 3: A differential drive WMR prototype with a power stage composed by DC/DC Buck power converters.

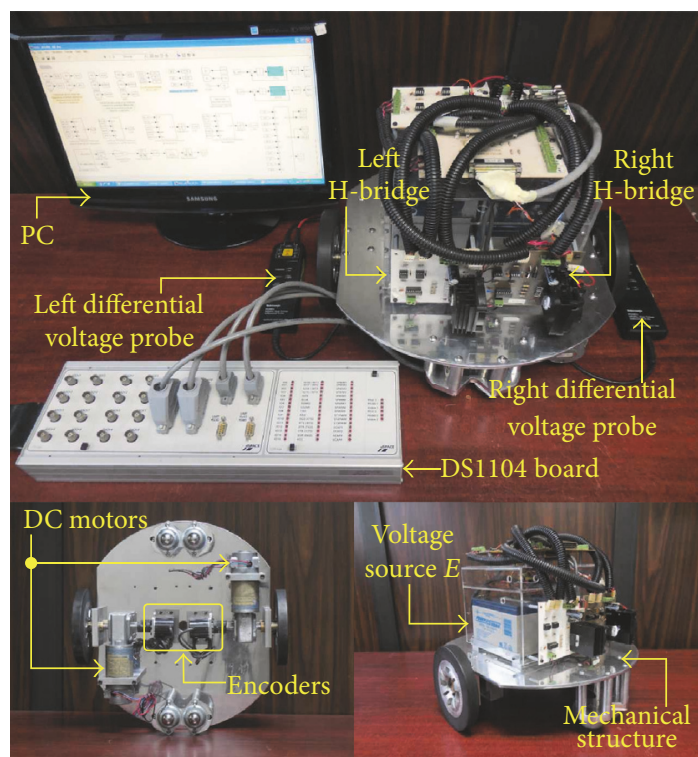

FIGURE 4: A differential drive WMR prototype with a power stage composed by H-bridges.

mass is $19 \mathrm{~kg}$. Parameters related to the wheels used in controls (8) and (9) are given by

$$
\begin{aligned}
r & =0.075 \mathrm{~m}, \\
2 l & =0.40 \mathrm{~m} .
\end{aligned}
$$

Both wheels of the prototype are actuated by brushed DC motors GNM3150+G2.6 $(24 \mathrm{~V}, 55 \mathrm{~W})$ which are provided with a 20:1 gearbox, whose angular velocities are measured via Autonics E50S8-1000 incremental encoders. Parameters associated with DC motors, used in (35) and (36), are

$$
\begin{aligned}
\mu_{r} & =10.2, \\
\gamma_{r} & =5.5, \\
\mu_{l} & =10.2, \\
\gamma_{l} & =6 .
\end{aligned}
$$

Likewise, each motor is driven by a DC/DC Buck power converter, whose voltages $\left(v_{r}, v_{l}\right)$ and currents $\left(i_{r}, i_{l}\right)$ are measured by Tektronix P5200A voltage probes and Tektronix A622 current probes, respectively. Parameters associated with Buck converters, used in switched controls (45), are

$$
\begin{aligned}
& L_{r}=10.129 \times 10^{-3} \mathrm{H}, \\
& L_{l}=10.6 \times 10^{-3} \mathrm{H}, \\
& C_{r}=C_{l}=220 \times 10^{-6} \mathrm{~F}, \\
& R_{r}=R_{l}=100 \Omega, \\
& E_{r}=E_{l}=28 \mathrm{~V} .
\end{aligned}
$$

Figure 3 also shows connections of the WMR prototype to the DS1104 board, Matlab-Simulink, and ControlDesk.

On the other hand, gains of the high-level controller (8) and (9) were selected as

$$
\begin{aligned}
& K_{1}=3, \\
& K_{2}=5, \\
& K_{3}=3,
\end{aligned}
$$


while gains associated with the medium-level controllers (35) and (36) were obtained by selecting their parameters as follows:

$$
\begin{gathered}
\xi_{1_{r}}=\xi_{1_{l}}=0.75, \\
\omega_{n_{1 r}}=\omega_{n_{1 l}}=20 .
\end{gathered}
$$

Lastly, gains of the low-level controllers (45) were proposed by choosing the following parameters:

$$
\begin{gathered}
a_{2_{r}}=a_{2_{l}}=180, \\
\xi_{2_{r}}=\xi_{2_{l}}=100, \\
\omega_{n_{2 r}}=\omega_{n_{2 l}}=200 .
\end{gathered}
$$

The desired trajectory that is imposed on the WMR is generated from the reference velocities $\nu^{*}$ and $\omega^{*}$ determined by the following Bézier polynomials:

$$
\begin{aligned}
& p_{\nu}(t)=\bar{\nu}\left(t_{i}\right)+\left[\bar{\nu}\left(t_{f}\right)-\bar{\nu}\left(t_{i}\right)\right] \psi\left(t, t_{i}, t_{f}\right), \\
& p_{\omega}(t)=\bar{\omega}\left(t_{i}\right)+\left[\bar{\omega}\left(t_{f}\right)-\bar{\omega}\left(t_{i}\right)\right] \psi\left(t, t_{i}, t_{f}\right),
\end{aligned}
$$

where $t_{i}$ and $t_{f}$ are the initial and final times of the given trajectory. Pairs $\left[\bar{\nu}\left(t_{i}\right), \bar{\nu}\left(t_{f}\right)\right]$ and $\left[\bar{\omega}\left(t_{i}\right), \bar{\omega}\left(t_{f}\right)\right]$ represent the constant linear and angular velocities which are joined smoothly through $p_{v}$ and $p_{\omega}$, respectively, over the time interval $\left[t_{i}, t_{f}\right]$. Function $\psi\left(t, t_{i}, t_{f}\right)$ is a polynomial given by

$$
\begin{aligned}
\psi\left(t, t_{i}, t_{f}\right) & \\
= & \left(\frac{t-t_{i}}{t_{f}-t_{i}}\right)^{3} \\
& \times\left[10-15\left(\frac{t-t_{i}}{t_{f}-t_{i}}\right)+6\left(\frac{t-t_{i}}{t_{f}-t_{i}}\right)^{2}\right] .
\end{aligned}
$$

The reference velocities $\nu^{*}$ and $\omega^{*}$ were generated using (53) according to Table 1 . Thus, by using (3), the trajectory to be tracked by the WMR in the $X Y$ plane, that is, $\left(x^{*}, y^{*}, \varphi^{*}\right)$, is depicted in subfigures (a) and (b) associated with Figures 5-9.

Figure 5 shows performance achieved under the variations given in Table 2 for the loads of the Buck converters. Figure 6 presents results when the abrupt variations defined in Table 3 are considered for the power supplies. Lastly, Figure 7 depicts results when the abrupt changes presented in Table 4 are considered for the inductances-capacitances of the Buck converters.

According to experimental results in Figures 5-7, the control objective is successfully achieved; that is, $(x, y, \varphi) \rightarrow$ $\left(x^{*}, y^{*}, \varphi^{*}\right)$. Furthermore, it can also be seen that the hierarchical controller is robust with respect to abrupt variations in the system parameters.

5.2. Experimental Results When the Power Stage Dynamics Is Neglected. The experimental implementation of controller reported in [98] is carried out in this section. The aim is to
TABLE 1: Desired trajectory defined by Bézier polynomials.

\begin{tabular}{lll}
\hline \multirow{2}{*}{$0 \leq t<0.4:$} & $v^{*}=p_{v}(t) ;$ & $\omega^{*}=0 ;$ \\
& $\bar{v}_{i}\left(t_{i}=0\right)=0.1 ;$ & \\
& $\bar{v}_{f}\left(t_{f}=0.4\right)=0.7 ;$ & \\
\hline $0.4 \leq t<1.3:$ & $v^{*}=0.7 ;$ & $\omega^{*}=0 ;$ \\
\hline \multirow{3}{*}{$v^{*}=t<1.8:$} & $\bar{v}_{i}\left(t_{i}=1.3\right)=0.7 ;$ & $\omega^{*}=p_{\omega}(t) ;$ \\
& $\bar{v}_{f}\left(t_{f}=1.8\right)=0.5 ;$ & $\bar{\omega}_{f}\left(t_{f}=1.8\right)=1.8 ;$ \\
\hline $1.8 \leq t<3.5:$ & $v^{*}=0.5 ;$ & $\omega^{*}=1.8 ;$ \\
\hline $3.5 \leq t<4.5:$ & $v^{*}=p_{v}(t) ;$ & $\omega^{*}=p_{\omega}(t) ;$ \\
& $\bar{v}_{i}\left(t_{i}=3.5\right)=0.5 ;$ & $\bar{\omega}_{i}\left(t_{i}=3.5\right)=1.8 ;$ \\
& $\bar{v}_{f}\left(t_{f}=4.5\right)=0.4 ;$ & $\bar{\omega}_{f}\left(t_{f}=4.5\right)=-1.8 ;$ \\
\hline $4.5 \leq t<5.5:$ & $v^{*}=0.4 ;$ & $\omega^{*}=-1.8 ;$ \\
\hline & $v^{*}=p_{v}(t) ;$ & $\omega^{*}=p_{\omega}(t) ;$ \\
& $\bar{v}_{i}\left(t_{i}=5.5\right)=0.4 ;$ & $\bar{\omega}_{i}\left(t_{i}=5.5\right)=-1.8 ;$ \\
& $\bar{v}_{f}\left(t_{f}=5.8\right)=0.3 ;$ & $\bar{\omega}_{f}\left(t_{f}=5.8\right)=-0.75 ;$ \\
\hline & $v^{*}=p_{v}(t) ;$ & $\omega^{*}=p_{\omega}(t) ;$ \\
& $\bar{v}_{i}\left(t_{i}=5.8\right)=0.3 ;$ & $\bar{\omega}_{i}\left(t_{i}=5.8\right)=-0.75 ;$ \\
& $\bar{v}_{f}\left(t_{f}=6\right)=0.2 ;$ & $\bar{\omega}_{f}\left(t_{f}=6\right)=-0.25$. \\
\hline
\end{tabular}

TABLE 2: Abrupt changes in $R_{r}$ and $R_{l}$.

\begin{tabular}{lll}
\hline$R_{m_{r}}$ & $R_{m_{l}}$ & Time interval \\
\hline$R_{r}$ & $R_{l}$ & $t<1 \mathrm{~s}$ \\
$9 \% R_{r}$ & $9 \% R_{l}$ & $1 \mathrm{~s} \leq t<3 \mathrm{~s}$ \\
$R_{r}$ & $R_{l}$ & $3 \mathrm{~s} \leq t<5 \mathrm{~s}$ \\
$9 \% R_{r}$ & $9 \% R_{l}$ & $5 \mathrm{~s} \leq t$ \\
\hline
\end{tabular}

TABle 3: Abrupt changes in $E_{r}$ and $E_{l}$.

\begin{tabular}{lll}
\hline$E_{m_{r}}$ & $E_{m_{l}}$ & Time interval \\
\hline$E_{r}$ & $E_{l}$ & $t<1 \mathrm{~s}$ \\
$75 \% E_{r}$ & $75 \% E_{l}$ & $1 \mathrm{~s} \leq t<3 \mathrm{~s}$ \\
$E_{r}$ & $E_{l}$ & $3 \mathrm{~s} \leq t<5 \mathrm{~s}$ \\
$75 \% E_{r}$ & $75 \% E_{l}$ & $5 \mathrm{~s} \leq t$ \\
\hline
\end{tabular}

TABle 4: Abrupt changes in $L_{r}, C_{r}, L_{l}$, and $C_{l}$.

\begin{tabular}{lllll}
\hline$L_{m_{r}}$ & $C_{m_{r}}$ & $L_{m_{l}}$ & $C_{m_{l}}$ & Time interval \\
\hline$L_{r}$ & $C_{r}$ & $L_{l}$ & $C_{l}$ & $t<1 \mathrm{~s}$ \\
$32 \% L_{r}$ & $33 \% C_{r}$ & $37 \% L_{l}$ & $33 \% C_{l}$ & $1 \mathrm{~s} \leq t<3 \mathrm{~s}$ \\
$L_{r}$ & $C_{r}$ & $L_{l}$ & $C_{l}$ & $3 \mathrm{~s} \leq t<5 \mathrm{~s}$ \\
$32 \% L_{r}$ & $33 \% C_{r}$ & $37 \% L_{l}$ & $33 \% C_{l}$ & $5 \mathrm{~s} \leq t$ \\
\hline
\end{tabular}

show that performance achieved with the hierarchical controller introduced in the present paper is better than, or at least similar to, performance achieved with controllers that do not consider the dynamics of the power stage [31103]. For such an aim, the differential drive WMR prototype depicted in Figure 4 was employed. It is stressed that power stage of this prototype is composed by $\mathrm{H}$-bridges instead of Buck converters. The physical characteristics of this WMR prototype are similar to those of the WMR prototype shown in Figure 3. Controller gains as well as trajectory to be tracked by the WMR prototype shown in Figure 4 are the same as those used in Section 5.1. 


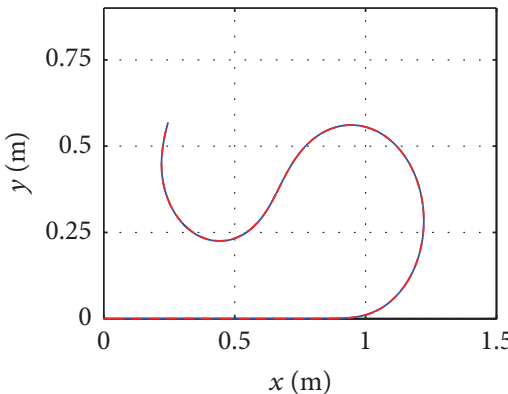

$-y^{*}\left(x^{*}\right)$

$--y(x)$

(a)

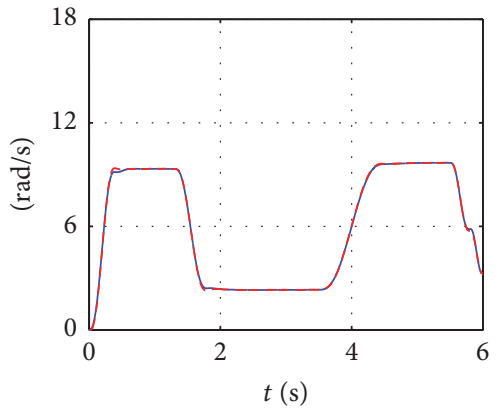

$\begin{aligned}- & \omega_{l} \\ -- & \omega_{l}\end{aligned}$

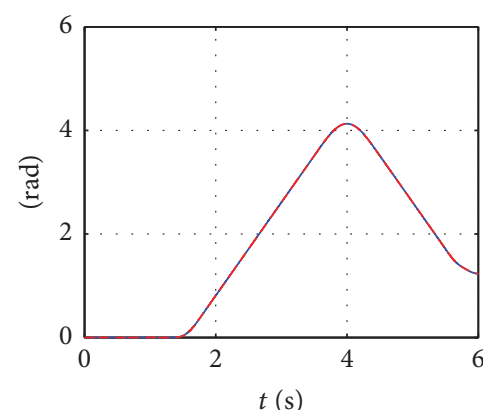

$-\varphi^{*}$
$--\varphi$

(b)
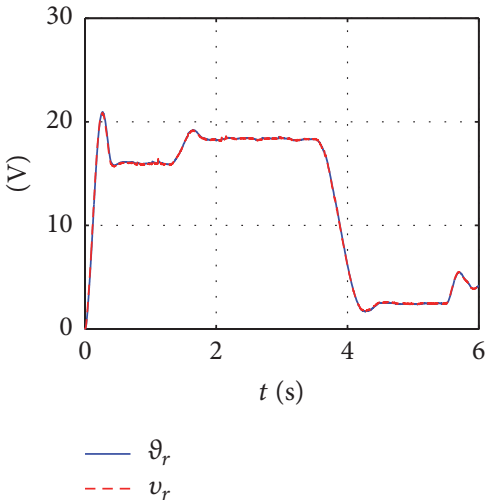

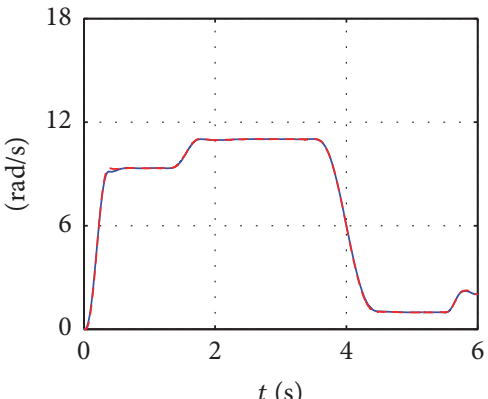

$-\omega_{r}$

$---\omega_{r}$

(c)
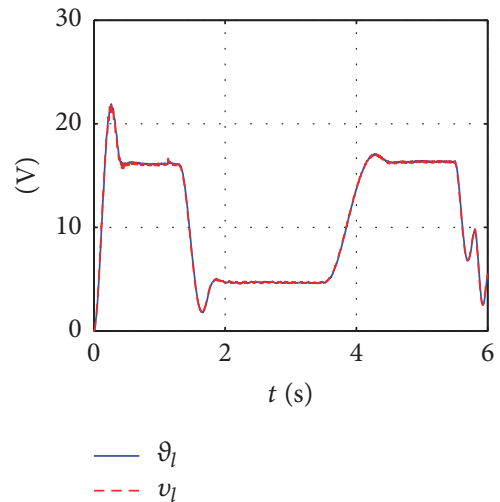

(f)

(d)

(e)

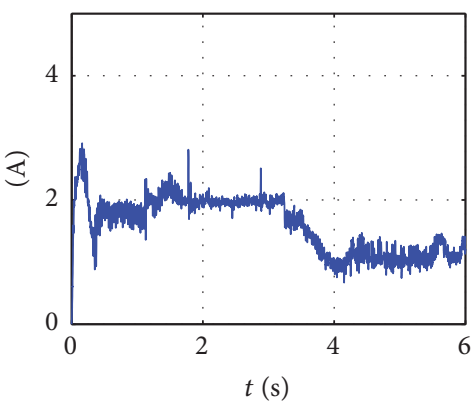

$-i_{r}$

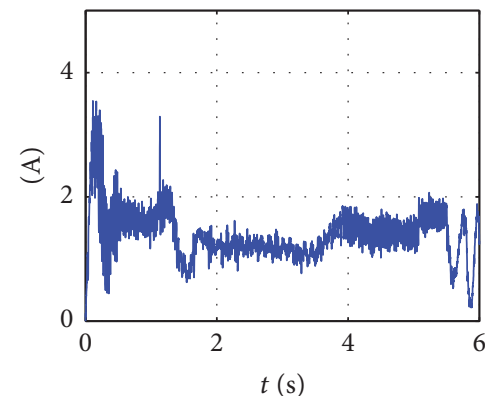

$-i_{l}$

(g)

(h)

FIGURE 5: Experimental results when uncertainties exist in $R_{r}$ and $R_{l}$.

TABle 5: Abrupt changes in $E_{r}$ and $E_{l}$.

\begin{tabular}{lll}
\hline$E_{m_{r}}$ & $E_{m_{l}}$ & Time interval \\
\hline$E_{r}$ & $E_{l}$ & $t<1 \mathrm{~s}$ \\
$87.5 \% E_{r}$ & $87.5 \% E_{l}$ & $1 \mathrm{~s} \leq t<3 \mathrm{~s}$ \\
$E_{r}$ & $E_{l}$ & $3 \mathrm{~s} \leq t<5 \mathrm{~s}$ \\
$87.5 \% E_{r}$ & $87.5 \% E_{l}$ & $5 \mathrm{~s} \leq t$ \\
\hline
\end{tabular}

When the power supplies are subject to variations defined in Table 3, the WMR shown in Figure 4 behaves as shown in Figure 8 . When the abrupt variations defined in Table 5 are considered now for the power supplies, the WMR behaves as depicted in Figure 9. As observed in Figure 8, controller fails when solving the trajectory tracking task if variations in power supplies are large enough (see Table 3). However, if the variations are much smaller (see Table 5 ), the control successfully solves such a task; that is, $(x, y, \varphi) \rightarrow\left(x^{*}, y^{*}, \varphi^{*}\right)$. See Figure 9.

\section{Conclusions}

A hierarchical controller solving the trajectory tracking task in a differential drive WMR has been introduced in this paper. 


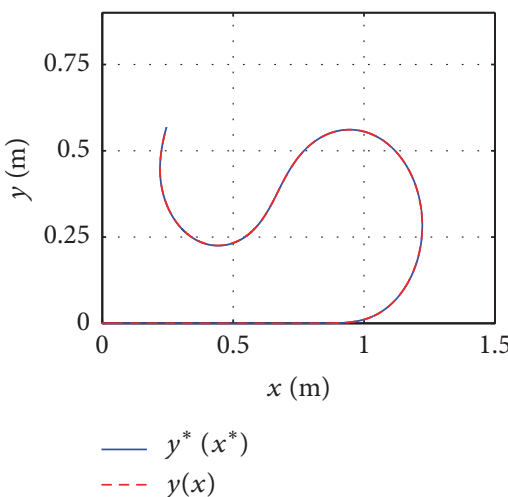

(a)
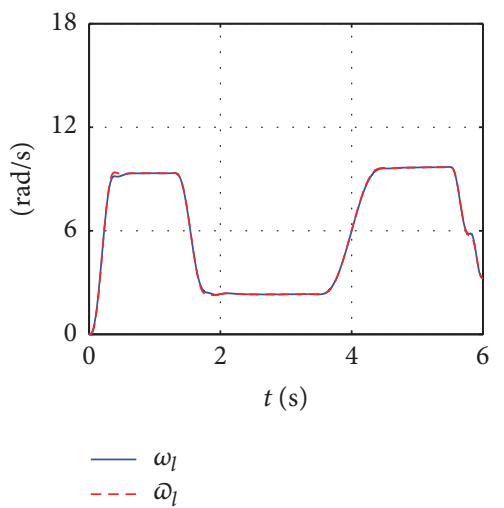
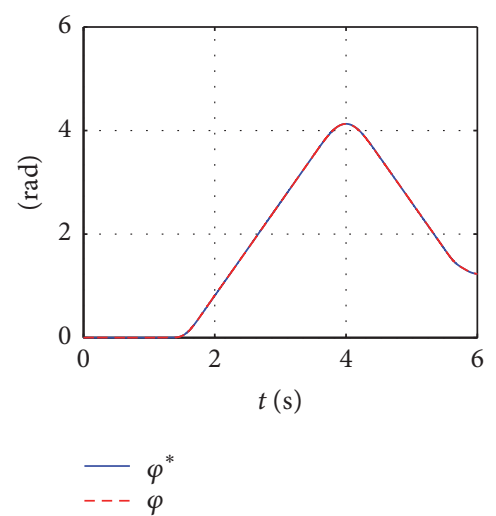

(b)

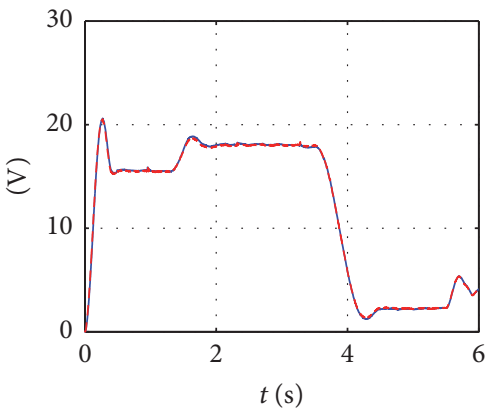

$\vartheta_{r}$
$--v_{r}$

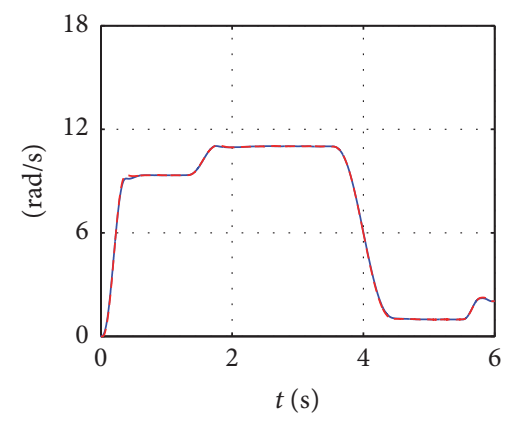

$-\omega_{r}$

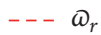

(c)

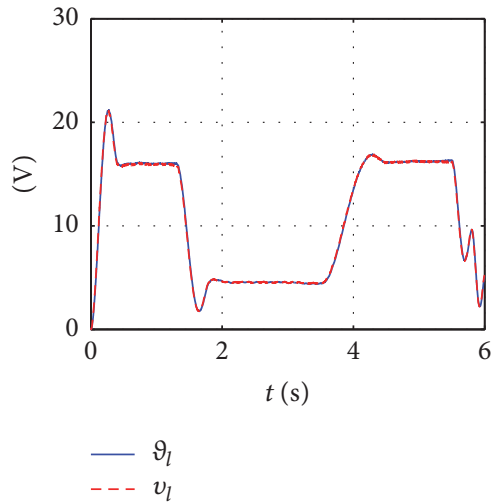

(f)

(d)

(e)

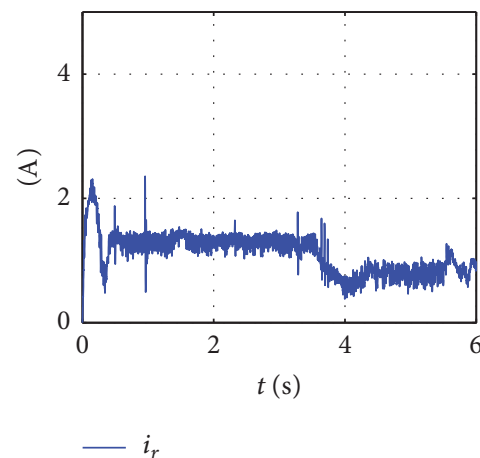

(g)

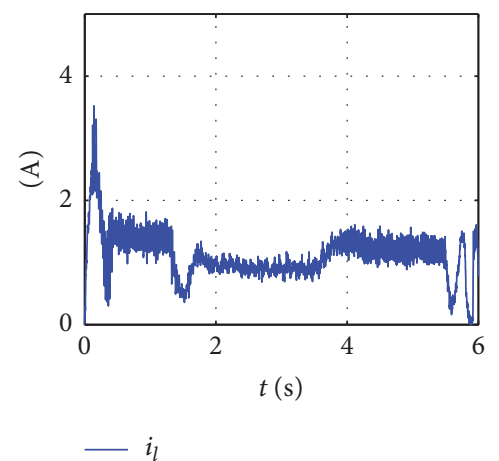

(h)

Figure 6: Experimental results when uncertainties exist in $E_{r}$ and $E_{l}$.

This control scheme is composed by a kinematic controller at the highest hierarchical level intended for the mechanical structure. Two differential flatness-based controllers are designed at the medium level intended for the WMR actuators (DC motors). Two average differential flatnessbased controllers are employed at the lowest hierarchical level intended for the power stage (Buck power converters). Hence, this is the first time that a trajectory tracking controller is designed for WMRs by taking into account the power stage dynamics during the design stage.

The closed-loop switched practical implementation was performed via $\Sigma-\Delta$-modulation in a differential drive WMR that was designed and built for such an aim. The experimental results confirm that the control objective is achieved; that is, $(x, y, \varphi) \rightarrow\left(x^{*}, y^{*}, \varphi^{*}\right)$, even when large, abrupt, and simultaneous changes appear in the system parameters. Additionally, the proposed controller was compared experimentally to a control scheme that neglects the power stage dynamics. According to experimental results, the proposal in the present paper achieves better performances.

Although the control objective is shown above to be achieved, the solution presented here only considers the unidirectional trajectory tracking task. Concerning this task, it is shown in [126] that this does not necessarily imply that robot is limited when tracking complex trajectories.

Future research will be focused on solving other control problems, such as obstacle avoidance and path-following, by using a similar approach to the one presented in this work. It 

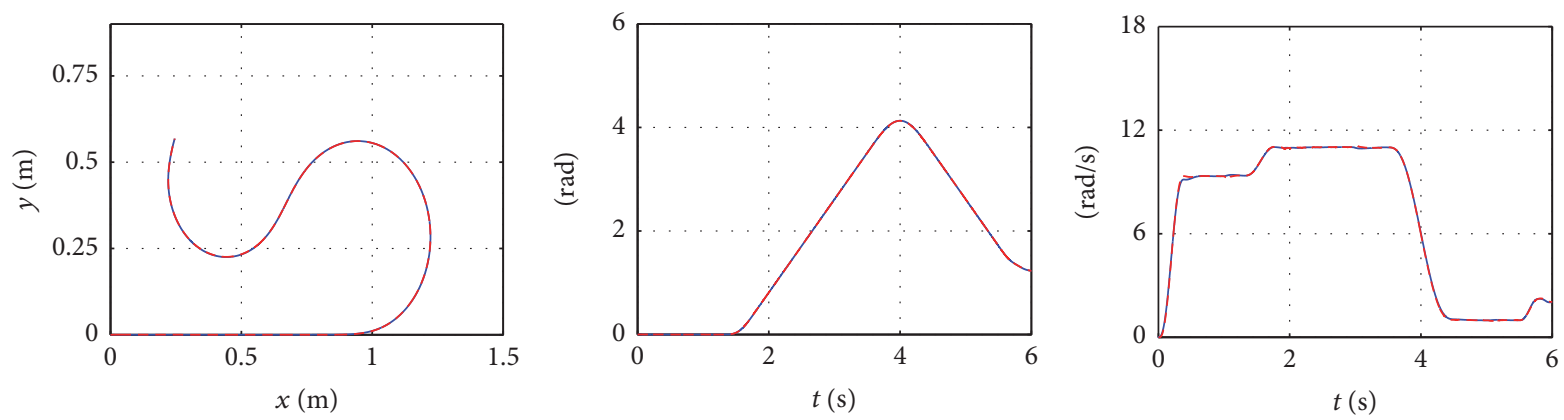

$-y^{*}\left(x^{*}\right)$

- - $y(x)$

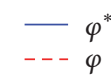

$-\omega_{r}$

$--\omega_{r}$

(a)

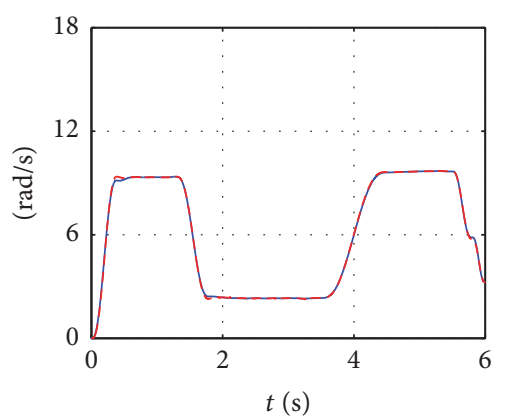

(b)

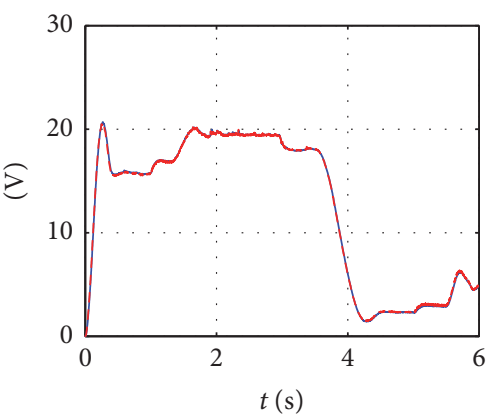

(c)

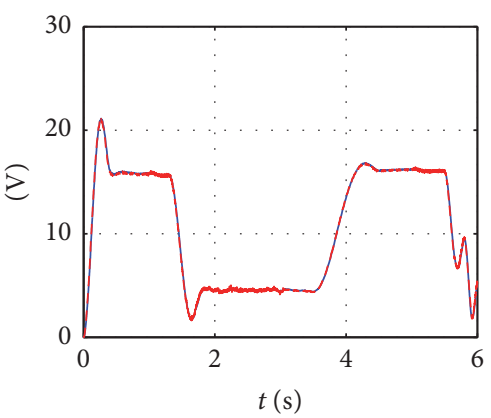

$-\omega_{l}$
$---\omega_{l}$

$\vartheta_{r}$
$---v_{r}$

$-\vartheta_{l}$

-- $v_{l}$

(d)

(e)

(f)

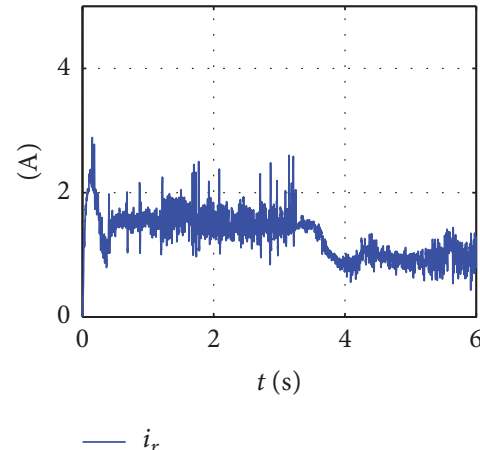

(g)

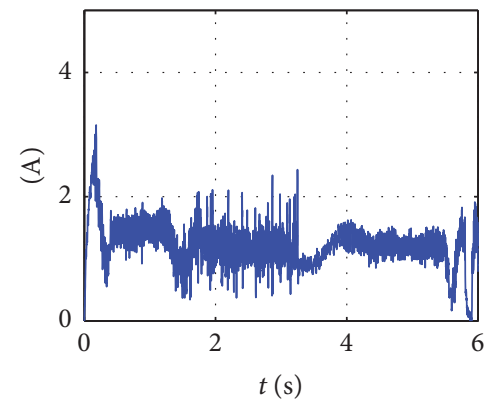

$-i_{l}$

(h)

FIGURE 7: Experimental results when abrupt changes associated with $L_{r}, C_{r}, L_{l}$, and $C_{l}$ appear.

would be convenient, however, that the robot power stage be redesigned in order to perform bidirectional trajectory tracking [127-129].

It is worth mentioning that recent important contributions on WMRs reported in the literature within the past few months do not take into account dynamics of the three subsystems composing a WMR (see [130-150]). In this respect, consideration of such dynamics in the design of controllers may lead to new research areas where power electronics would play a very important role.

\section{Conflicts of Interest}

The authors declare that the research was conducted in the absence of any commercial, financial, or personal relationships that could be construed as potential conflicts of interest.

\section{Acknowledgments}

This work was supported by Secretaría de Investigación y Posgrado del Instituto Politécnico Nacional, México. The work 


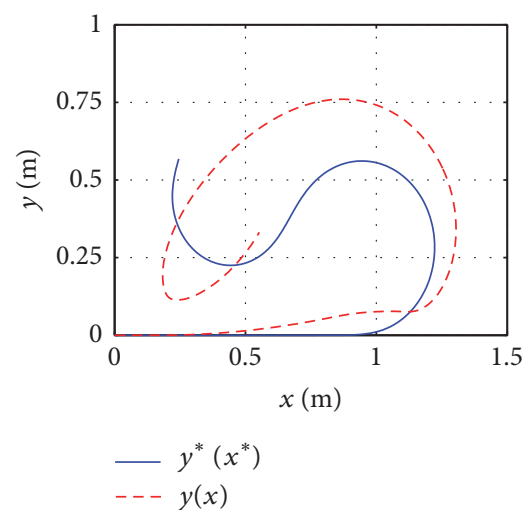

(a)

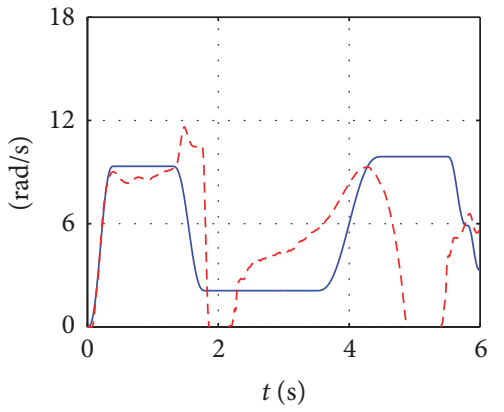

$-\omega_{l}$
$---\omega_{l}$

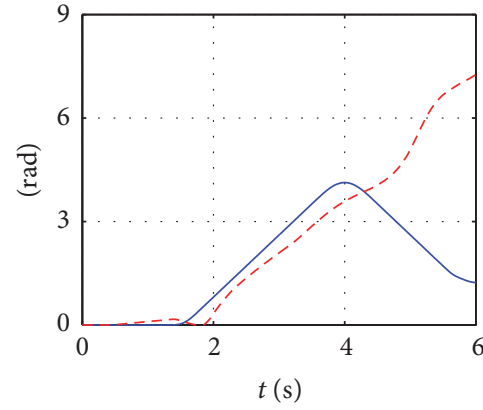

$-\varphi^{*}$

(b)

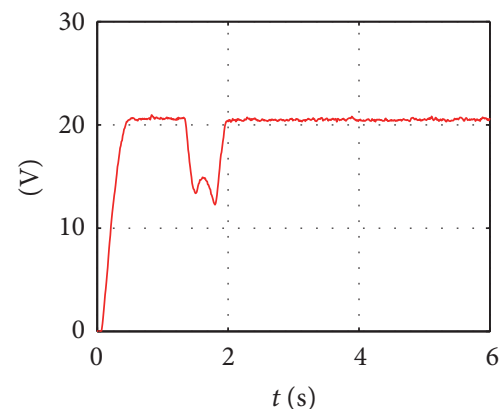

$-v_{r}$

(d)

(e)

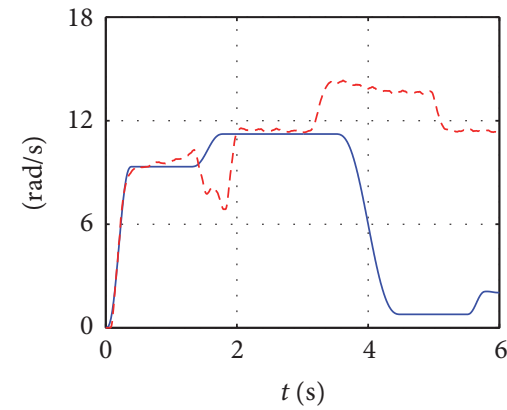

$-\omega_{r}$
$--\omega_{r}$

(c)

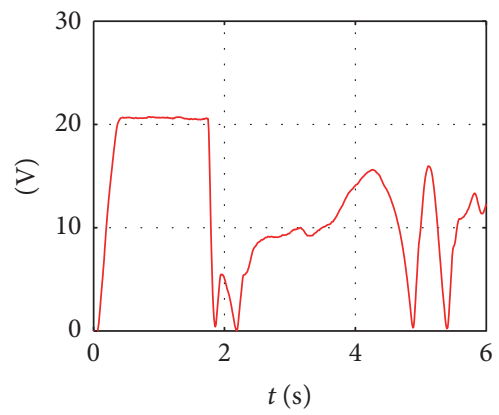

$-v_{l}$

(f)

FIGURE 8: Control objective is not accomplished when abrupt changes in Table 3, that is, associated with $E$, appear.
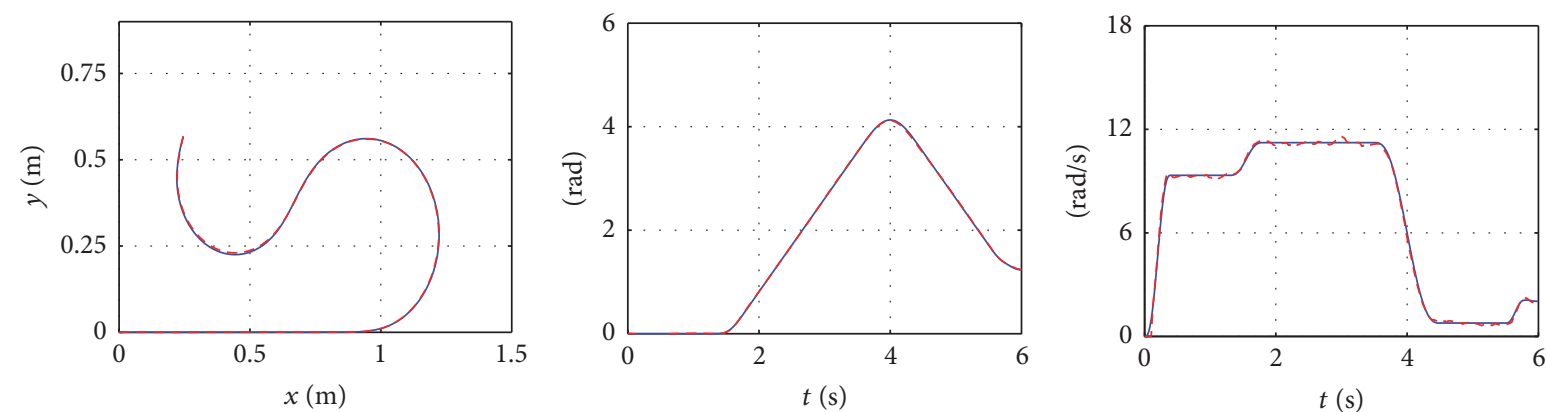

$y^{*}\left(x^{*}\right)$

- - $y(x)$

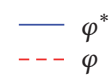

$-\omega_{r}$

(b)
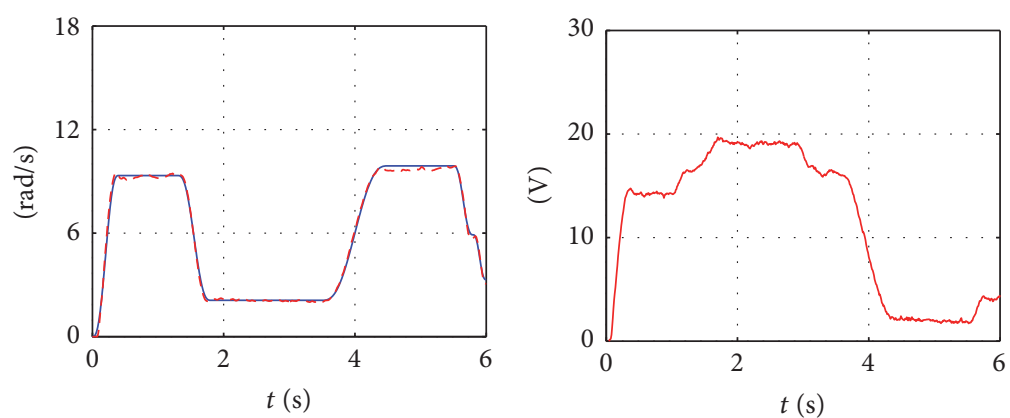

(c)

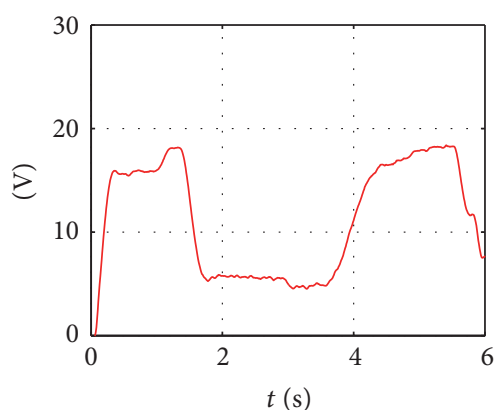

$\begin{aligned}- & \omega_{l} \\ --- & \omega_{l}\end{aligned}$

$-v_{r}$

$-v_{l}$

(f)

FIGURE 9: Control objective is accomplished when abrupt changes associated with $E$ are small (see Tables 3 and 5). 
of José Rafael García-Sánchez, Salvador Tavera-Mosqueda, Celso Márquez-Sánchez, and Mayra Antonio-Cruz was supported by CONACYT-México, and BEIFI scholarships. Ramón Silva-Ortigoza and Hind Taud acknowledge financial support from the IPN programs EDI and SIBE and from SNI-México. Lastly, Victor Manuel Hernández-Guzmán and Gilberto Silva-Ortigoza acknowledge SNI-México, for financial support.

\section{References}

[1] R. Siegwart and I. R. Nourbakhsh, Introduction to Autonomous Mobile Robots, MIT Press, Cambridge, MA, USA, 2004.

[2] F. Fahimi, Autonomous Robots: Modeling, Path Planning, and Control, Springer-Verlag, NY, USA, 2009.

[3] R. Silva-Ortigoza, M. Marcelino-Aranda, G. Silva-Ortigoza et al., "Wheeled mobile robots: a review," IEEE Latin America Transactions, vol. 10, no. 6, pp. 2209-2217, 2012.

[4] G. Bekey and J. Yuh, "The status of robotics," IEEE Robotics and Automation Magazine, vol. 15, no. 1, pp. 80-86, 2008.

[5] B. Siciliano and O. Khatib, Eds., Handbook of Robotics, SpringerVerlag, Berlin, Heidelberg, DE, 2008.

[6] A. Harris and J. M. Conrad, "Survey of popular robotics simulators, frameworks, and toolkits," in Proceedings of the IEEE SoutheastCon 2011 - Building Global Engineers, pp. 243-249, Nashville, TN, USA, 2011.

[7] K. Yoshida and S. Tadokoro, Eds., Field and Service Robotics, Springer-Verlag, NY, USA, 2014.

[8] A. M. Bloch, M. Reyhanoglu, and N. H. McClamroch, "Control and stabilization of nonholonomic dynamic systems," IEEE Transactions on Automatic Control, vol. 37, no. 11, pp. 1746-1757, 1992.

[9] I. Kolmanovsky and N. H. McClamroch, "Developments in nonholonomic control problems," IEEE Control Systems Magazine, vol. 15, no. 6, pp. 20-36, 1995.

[10] K. Erenturk, "Hybrid control of a mechatronic system: fuzzy logic and grey system modeling approach," IEEE/ASME Transactions on Mechatronics, vol. 12, no. 6, pp. 703-710, 2007.

[11] S. R. Bull, "Renewable energy today and tomorrow," Proceedings of the IEEE, vol. 89, no. 8, pp. 1216-1226, 2001.

[12] A. B. Stambouli and E. Traversa, "Fuel cells, an alternative to standard sources of energy," Renewable \& Sustainable Energy Reviews, vol. 6, no. 3, pp. 295-304, 2002.

[13] S. Rahman, "Green power: what is it and where can we find it?" IEEE Power \& Energy Magazine, vol. 1, no. 1, pp. 30-37, 2003.

[14] Z. L. Wang and J. Song, "Piezoelectric nanogenerators based on zinc oxide nanowire arrays," Science, vol. 312, no. 5771, pp. 242246, 2006.

[15] F. Blaabjerg and K. Ma, "Future on power electronics for wind turbine systems," IEEE Journal of Emerging and Selected Topics in Power Electronics, vol. 1, no. 3, pp. 139-152, 2013.

[16] O. Abedinia, A. Ghasemi, and N. Ojaroudi, "Improved time varying inertia weight $\mathrm{PSO}$ for solved economic load dispatch with subsidies and wind power effects," Complexity, vol. 21, no. 4, pp. 40-49, 2014.

[17] J. Widén, N. Carpman, V. Castellucci et al., "Variability assessment and forecasting of renewables: A review for solar, wind, wave and tidal resources," Renewable \& Sustainable Energy Reviews, vol. 44, pp. 356-375, 2015.
[18] S. Sivakumar, M. J. Sathik, P. S. Manoj, and G. Sundararajan, "An assessment on performance of DC-DC converters for renewable energy applications," Renewable \& Sustainable Energy Reviews, vol. 58, pp. 1475-1485, 2016.

[19] T. M. Pinho, J. P. Coelho, G. Veiga, A. P. Moreira, and J. Boaventura-Cunha, "A multilayer model predictive control methodology applied to a biomass supply chain operational level," Complexity, Article ID 5402896, 10 pages, 2017.

[20] B. K. Bose, "Energy, environment, and advances in power electronics," IEEE Transactions on Power Electronics, vol. 15, no. 4, pp. 688-701, 2000.

[21] F. Blaabjerg, Z. Chen, and S. B. Kjaer, "Power electronics as efficient interface in dispersed power generation systems," IEEE Transactions on Power Electronics, vol. 19, no. 5, pp. 1184-1194, 2004.

[22] J. M. Carrasco, L. G. Franquelo, J. T. Bialasiewicz et al., "Power electronic systems for the grid integration of renewable energy sources: a survey," IEEE Transactions on Industrial Electronics, vol. 53, no. 4, pp. 1002-1016, 2006.

[23] A. Emadi, Y. J. Lee, and K. Rajashekara, "Power electronics and motor drives in electric, hybrid electric, and plug-in hybrid electric vehicles," IEEE Transactions on Industrial Electronics, vol. 55, no. 6, pp. 2237-2245, 2008.

[24] S. Vazquez, S. M. Lukic, E. Galván, L. G. Franquelo, and J. M. Carrasco, "Energy storage systems for transport and grid applications," IEEE Transactions on Industrial Electronics, vol. 57, no. 12, pp. 3881-3895, 2010.

[25] J. D. van Wyk and F. C. Lee, "On a future for power electronics," IEEE Journal of Emerging and Selected Topics in Power Electronics, vol. 1, no. 2, pp. 59-72, 2013.

[26] J. Hu, J. Cao, and T. Yong, "Multi-level dispatch control architecture for power systems with demand-side resources," IET Generation, Transmission \& Distribution, vol. 9, no. 16, pp. 2799-2810, 2015.

[27] O. Abedinia and N. Amjady, "Net demand prediction for power systems by a new neural network-based forecasting engine," Complexity, vol. 21, no. S2, pp. 296-308, 2016.

[28] J. Hu, M. Z. Q. Chen, J. Cao, and J. M. Guerrero, "Coordinated active power dispatch for a microgrid via distributed lambda iteration," IEEE Journal on Emerging and Selected Topics in Circuits and Systems, vol. 7, no. 2, pp. 250-261, 2017.

[29] M. Godoy Simoẽs, N. Franceschetti, and J. Adamowski, "Drive system control and energy management of a solar powered electric vehicle," in Proceedings of the APEC '98 Thirteenth Annual Applied Power Electronics Conference and Exposition, pp. 49-55, Anaheim, CA, USA, 1998.

[30] S. A. KH. Mozaffari Niapour, S. Danyali, M. B. B. Sharifian, and M. R. Feyzi, "Brushless DC motor drives supplied by PV power system based on Z-source inverter and FL-IC MPPT controller," Energy Conversion and Management, vol. 52, no. 8-9, pp. 30433059, 2011.

[31] Y. Kanayama, Y. Kimura, F. Miyazaki, and T. Noguchi, "A stable tracking control method for an autonomous mobile robot," in Proceedings of the IEEE International Conference on Robotics and Automation, pp. 384-389, Cincinnati, OH, USA, 1990.

[32] C. Samson and K. Ait-Abderrahim, "Feedback control of a nonholonomic wheeled cart in cartesian space," in Proceedings of IEEE the International Conference on Robotics and Automation 1991, pp. 1136-1141, Sacramento, CA, USA, 1991.

[33] R. M. Murray and S. S. Sastry, "Nonholonomic motion planning: steering using sinusoids," IEEE Transactions on Automatic Control, vol. 38, no. 5, pp. 700-716, 1993. 
[34] J. Chacal B. and H. Sira-Ramírez, "On the sliding mode control of wheeled mobile robots," in Proceedings of the IEEE International Conference on Systems, Man and Cybernetics, pp. 1938-1943, San Antonio, TX, USA, 1994.

[35] G. Walsh, D. Tilbury, S. Sastry, R. Murray, and J. P. Laumond, "Stabilization of trajectories for systems with nonholonomic constraints," IEEE Transactions on Automatic Control, vol. 39, no. 1, pp. 216-222, 1994.

[36] Z.-P. Jiang and H. Nijmeijer, "Tracking control of mobile robots: a case study in backstepping," Automatica, vol. 33, no. 7, pp. 1393-1399, 1997.

[37] D.-H. Kim and J.-H. Oh, "Tracking control of a two-wheeled mobile robot using input-output linearization," Control Engineering Practice, vol. 7, no. 3, pp. 369-373, 1999.

[38] Z.-P. Jiang and H. Nijmeijer, "A recursive technique for tracking control of nonholonomic systems in chained form," IEEE Transactions on Automatic Control, vol. 44, no. 2, pp. 265-279, 1999.

[39] W. E. Dixon, D. M. Dawson, E. Zergeroglu, and F. Zhang, "Robust tracking and regulation control for mobile robots," International Journal of Robust and Nonlinear Control, vol. 10, no. 4, pp. 199-216, 2000.

[40] W. E. Dixon, D. M. Dawson, F. Zhang, and E. Zergeroglu, "Global exponential tracking control of a mobile robot system via a PE condition," IEEE Transactions on Systems, Man, and Cybernetics, Part B: Cybernetics, vol. 30, no. 1, pp. 129-142, 2000.

[41] W. E. Dixon, D. M. Dawson, and E. Zergeroglu, “Tracking and regulation control of a mobile robot system with kinematic disturbances: a variable structure-like approach," Journal of Dynamic Systems, Measurement, and Control, vol. 122, no. 4, pp. 616-623, 2000.

[42] T.-C. Lee, K.-T. Song, C.-H. Lee, and C.-C. Teng, "Tracking control of unicycle-modeled mobile robots using a saturation feedback controller," IEEE Transactions on Control Systems Technology, vol. 9, no. 2, pp. 305-318, 2001.

[43] D. Chwa, "Sliding-mode tracking control of nonholonomic wheeled mobile robots in polar coordinates," IEEE Transactions on Control Systems Technology, vol. 12, no. 4, pp. 637-644, 2004.

[44] G. Klančar and I. Škrjanc, "Tracking-error model-based predictive control for mobile robots in real time," Robotics and Autonomous Systems, vol. 55, no. 6, pp. 460-469, 2007.

[45] C.-Y. Tsai, K.-T. Song, X. Dutoit, H. Van Brussel, and M. Nuttin, "Robust visual tracking control system of a mobile robot based on a dual-Jacobian visual interaction model," Robotics and Autonomous Systems, vol. 57, no. 6-7, pp. 652-664, 2009.

[46] J. H. Lee, C. Lin, H. Lim, and J. M. Lee, "Sliding mode control for trajectory tracking of mobile robot in the RFID sensor space," International Journal of Control, Automation, and Systems, vol. 7, no. 3, pp. 429-435, 2009.

[47] G. Scaglia, A. Rosales, L. Quintero, V. Mut, and R. Agarwal, "A linear-interpolation-based controller design for trajectory tracking of mobile robots," Control Engineering Practice, vol. 18, no. 3, pp. 318-329, 2010.

[48] L. Cheng, L. Cao, H.-Y. Wu, Q.-M. Zhu, W.-X. Xu, and L. Liu, "Trajectory tracking control of nonholonomic mobile robots by backstepping," in Proceedings of the 2011 International Conference on Modelling, Identification and Control, pp. 134-139, Shanghai, China, 2011.

[49] D. Chwa, "Fuzzy adaptive tracking control of wheeled mobile robots with state-dependent kinematic and dynamic disturbances," IEEE Transactions on Fuzzy Systems, vol. 20, no. 3, pp. 587-593, 2012.
[50] C. Canudas de Wit and O. J. Sørdalen, "Exponential stabilization of mobile robots with nonholonomic constraints," IEEE Transactions on Automatic Control, vol. 37, no. 11, pp. 1791-1797, 1992.

[51] G. Oriolo, A. De Luca, and M. Vendittelli, "WMR control via dynamic feedback linearization: Design, implementation, and experimental validation," IEEE Transactions on Control Systems Technology, vol. 10, no. 6, pp. 835-852, 2002.

[52] S. Sun, "Designing approach on trajectory-tracking control of mobile robot," Robotics and Computer-Integrated Manufacturing, vol. 21, no. 1, pp. 81-85, 2005.

[53] D. Gu and H. Hu, "Receding horizon tracking control of wheeled mobile robots," IEEE Transactions on Control Systems Technology, vol. 14, no. 4, pp. 743-749, 2006.

[54] M. Defoort, T. Floquet, A. Kökösy, and W. Perruquetti, "Slidingmode formation control for cooperative autonomous mobile robots," IEEE Transactions on Industrial Electronics, vol. 55, no. 11, pp. 3944-3953, 2008.

[55] R.-J. Wai and C.-M. Liu, "Design of dynamic petri recurrent fuzzy neural network and its application to path-tracking control of nonholonomic mobile robot," IEEE Transactions on Industrial Electronics, vol. 56, no. 7, pp. 2667-2683, 2009.

[56] J. Wang, Z. Lu, W. Chen, and X. Wu, "An adaptive trajectory tracking control of wheeled mobile robots," in Proceedings of the 2011 6th IEEE Conference on Industrial Electronics and Applications, ICIEA 2011, pp. 1156-1160, Beijing, China, 2011.

[57] S. Blažič, "A novel trajectory-tracking control law for wheeled mobile robots," Robotics and Autonomous Systems, vol. 59, no. 11, pp. 1001-1007, 2011.

[58] M. H. Amoozgar and Y. M. Zhang, "Trajectory tracking of wheeled mobile robots: a kinematical approach," in Proceedings of the 2012 8th IEEE/ASME International Conference on Mechatronic and Embedded Systems and Applications, MESA 2012, pp. 275-280, Suzhou, China, 2012.

[59] S. Blažič, "On periodic control laws for mobile robots," IEEE Transactions on Industrial Electronics, vol. 61, no. 7, pp. 36603670, 2014.

[60] B. d'Andréa-Novel, G. Bastin, and G. Campion, "Modelling and control of non-holonomic wheeled mobile robots," in Proceedings of the 1991 IEEE International Conference on Robotics and Automation, pp. 1130-1135, Sacramento, CA, USA, 1991.

[61] R. Fierro and F. Lewis, "Control of a nonholonomic mobile robot: backstepping kinematics into dynamics," in Proceedings of the 1995 34th IEEE Conference on Decision and Control, pp. 3805-3810, New Orleans, LA, USA, 1995.

[62] J.-M. Yang and J.-H. Kim, "Sliding mode control for trajectory tracking of nonholonomic wheeled mobile robots," IEEE Transactions on Robotics and Automation, vol. 15, no. 3, pp. 578-587, 1999.

[63] W. Dong, W. L. Xu, and W. Huo, "Trajectory tracking control of dynamic non-holonomic systems with unknown dynamics," International Journal of Robust and Nonlinear Control, vol. 9, no. 13, pp. 905-922, 1999.

[64] W. E. Dixon, D. M. Dawson, E. Zergeroglu, and A. Behal, "Adaptive tracking control of a wheeled mobile robot via an uncalibrated camera system," IEEE Transactions on Systems, Man, and Cybernetics, Part B: Cybernetics, vol. 31, no. 3, pp. 341352, 2001.

[65] F. Pourboghrat and M. P. Karlsson, "Adaptive control of dynamic mobile robots with nonholonomic constraints," Computers and Electrical Engineering, vol. 28, no. 4, pp. 241-253, 2002. 
[66] W. Dong and K.-D. Kuhnert, "Robust adaptive control of nonholonomic mobile robot with parameter and nonparameter uncertainties," IEEE Transactions on Robotics, vol. 21, no. 2, pp. 261-266, 2005.

[67] C.-Y. Chen, T.-H. S. Li, Y.-C. Yeh, and C.-C. Chang, "Design and implementation of an adaptive sliding-mode dynamic controller for wheeled mobile robots," Mechatronics, vol. 19, no. 2, pp. 156-166, 2009.

[68] R. Solea, A. Filipescu, and U. Nunes, "Sliding-mode control for trajectory-tracking of a wheeled mobile robot in presence of uncertainties," in Proceedings of the 7th Asian Control Conference, pp. 1701-1706, Hong Kong, China, 2009.

[69] Z. Cao, Y. Zhao, and Q. Wu, "Adaptive trajectory tracking control for a nonholonomic mobile robot," Chinese Journal of Mechanical Engineering, vol. 24, no. 4, pp. 546-552, 2011.

[70] K. Shojaei, A. M. Shahri, and B. Tabibian, "Design and implementation of an inverse dynamics controller for uncertain nonholonomic robotic systems," Journal of Intelligent \& Robotic Systems, vol. 71, no. 1, pp. 65-83, 2013.

[71] T. Fukao, H. Nakagawa, and N. Adachi, "Adaptive tracking control of a nonholonomic mobile robot," IEEE Transactions on Robotics and Automation, vol. 16, no. 5, pp. 609-615, 2000.

[72] C. de Sousa Jr., E. M. Hemerly, and R. K. H. Galvão, "Adaptive control for mobile robot using wavelet networks," IEEE Transactions on Systems, Man, and Cybernetics, Part B: Cybernetics, vol. 32, no. 4, pp. 493-504, 2002.

[73] W. E. Dixon, M. S. de Queiroz, D. M. Dawson, and T. J. Flynn, "Adaptive tracking and regulation of a wheeled mobile robot with controller/update law modularity," IEEE Transactions on Control Systems Technology, vol. 12, no. 1, pp. 138-147, 2004.

[74] K. Morioka, J.-H. Lee, and H. Hashimoto, "Human-following mobile robot in a distributed intelligent sensor network," IEEE Transactions on Industrial Electronics, vol. 51, no. 1, pp. 229-237, 2004.

[75] T.-J. Ren, T.-C. Chen, and C.-J. Chen, "Motion control for a two-wheeled vehicle using a self-tuning PID controller," Control Engineering Practice, vol. 16, no. 3, pp. 365-375, 2008.

[76] F. N. Martins, W. C. Celeste, R. Carelli, M. Sarcinelli-Filho, and T. F. Bastos-Filho, "An adaptive dynamic controller for autonomous mobile robot trajectory tracking," Control Engineering Practice, vol. 16, no. 11, pp. 1354-1363, 2008.

[77] B. S. Park, S. J. Yoo, J. B. Park, and Y. H. Choi, "Adaptive neural sliding mode control of nonholonomic wheeled mobile robots with model uncertainty," IEEE Transactions on Control Systems Technology, vol. 17, no. 1, pp. 207-214, 2009.

[78] D. Chwa, "Tracking control of differential-drive wheeled mobile robots using a backstepping-like feedback linearization," IEEE Transactions on Systems, Man, and Cybernetics, Part A: Systems and Humans, vol. 40, no. 6, pp. 1285-1295, 2010.

[79] H.-S. Kang, Y.-T. Kim, C.-H. Hyun, and M. Park, “Generalized extended state observer approach to robust tracking control for wheeled mobile robot with skidding and slipping," International Journal of Advanced Robotic Systems, vol. 10, no. 3, pp. 1-10, 2013.

[80] J. Huang, C. Wen, W. Wang, and Z.-P. Jiang, "Adaptive output feedback tracking control of a nonholonomic mobile robot," Automatica, vol. 50, no. 3, pp. 821-831, 2014.

[81] C. Aguilar-Avelar and J. Moreno-Valenzuela, "A MRAC principle for a single-link electrically driven robot with parameter uncertainties," Complexity, Article ID 9296012, 13 pages, 2017.

[82] M. C. Good, L. M. Sweet, and K. L. Strobel, "Dynamic models for control system design of integrated robot and drive systems,"
Journal of Dynamic Systems, Measurement, and Control, vol. 107, no. 1, pp. 53-59, 1985.

[83] T. Tarn, A. K. Bejczy, X. Yun, and Z. Li, "Effect of motor dynamics on nonlinear feedback robot arm control," IEEE Transactions on Robotics and Automation, vol. 7, no. 1, pp. 114122, 1991.

[84] C.-L. Hwang, "Comparison of path tracking control of a car-like mobile robot with and without motor dynamics," IEEE/ASME Transactions on Mechatronics, vol. 21, no. 4, pp. 1801-1811, 2016.

[85] F. Espinosa, E. López, R. Mateos, M. Mazo, and R. García, "Advanced and intelligent control techniques applied to the drive control and path tracking systems on a robotic wheelchair," Autonomous Robots, vol. 11, no. 2, pp. 137-148, 2001.

[86] R. Silva-Ortigoza, G. Silva-Ortigoza, V. M. HernándezGuzmán, V. R. Barrientos-Sotelo, J. M. Albarrán-Jiménez, and V. M. Silva-Garcia, "Trajectory tracking in a mobile robot without using velocity measurements for control of wheels," IEEE Latin America Transactions, vol. 6, no. 7, pp. 598-607, 2008.

[87] Y. Zuo, Y. Wang, X. Liu et al., "Neural network robust control for a nonholonomic mobile robot including actuator dynamics," International Journal of Innovative Computing, Information and Control, vol. 6, no. 8, pp. 3437-3449, 2010.

[88] R. Silva-Ortigoza, C. Márquez-Sánchez, M. Marcelino-Aranda et al., "Construction of a WMR for trajectory tracking control: Experimental results," The Scientific World Journal, vol. 2013, Article ID 723645, 2013.

[89] L. M. Sweet and M. C. Good, "Redefinition of the robot motioncontrol problem," IEEE Control Systems Magazine, vol. 5, no. 3, pp. 18-25, 1985.

[90] C. M. Anupoju, C.-Y. Su, and M. Oya, "Adaptive motion tracking control of uncertain nonholonomic mechanical systems including actuator dynamics," IEE Proceedings - Control Theory and Applications, vol. 152, no. 5, pp. 575-580, 2005.

[91] T. Das and I. N. Kar, "Design and implementation of an adaptive fuzzy logic-based controller for wheeled mobile robots," IEEE Transactions on Control Systems Technology, vol. 14, no. 3, pp. 501-510, 2006.

[92] Z.-G. Hou, A.-M. Zou, L. Cheng, and M. Tan, "Adaptive control of an electrically driven nonholonomic mobile robot via backstepping and fuzzy approach," IEEE Transactions on Control Systems Technology, vol. 17, no. 4, pp. 803-815, 2009.

[93] S. Luo, S. Wu, Z. Liu, and H. Guan, "Wheeled mobile robot RBFNN dynamic surface control based on disturbance observer," ISRN Applied Mathematics, vol. 2014, Article ID 634936, 9 pages, 2014.

[94] K. Kozlowski and J. Majchrzak, "A backstepping approach to control a nonholonomic mobile robot," in Proceedings of the IEEE International Conference on Robotics and Automation 2002, pp. 3972-3977, Washington D.C., USA, 2002.

[95] T. Das, I. N. Kar, and S. Chaudhury, "Simple neuron-based adaptive controller for a nonholonomic mobile robot including actuator dynamics," Neurocomputing, vol. 69, no. 16-18, pp. 2140-2151, 2006.

[96] N. A. Martins, D. W. Bertol, E. R. de Pieri, E. B. Castelan, and M. M. Dias, "Neural dynamic control of a nonholonomic mobile robot incorporating the actuator dynamics," in Proceedings of the 2008 International Conference on Computational Intelligence for Modelling Control and Automation, CIMCA 2008, pp. 563568, Vienna, Austria, 2008.

[97] B. S. Park, S. J. Yoo, J. B. Park, and Y. H. Choi, "Adaptive tracking control of nonholonomic mobile robots considering actuator 
dynamics: Dynamic surface design approach," in Proceedings of the 2009 American Control Conference, ACC 2009, pp. 38603865, St. Louis, MO, USA, 2009.

[98] J. L. Avendaño-Juárez, V. M. Hernández-Guzmán, and R. SilvaOrtigoza, "Velocity and current inner loops in a wheeled mobile robot," Advanced Robotics, vol. 24, no. 8-9, pp. 1385-1404, 2010.

[99] B. S. Park, S. J. Yoo, J. B. Park, and Y. H. Choi, "A simple adaptive control approach for trajectory tracking of electrically driven nonholonomic mobile robots," IEEE Transactions on Control Systems Technology, vol. 18, no. 5, pp. 1199-1206, 2010.

[100] I. Zohar, A. Ailon, and R. Rabinovici, "Mobile robot characterized by dynamic and kinematic equations and actuator dynamics: trajectory tracking and related application," Robotics and Autonomous Systems, vol. 59, no. 6, pp. 343-353, 2011.

[101] K. Shojaei and A. M. Shahri, "Output feedbak tracking control of uncertain non-holonomic wheeled mobile robots: a dynamic surface control approach," IET Control Theory \& Applications, vol. 6, no. 2, pp. 216-228, 2012.

[102] C.-L. Hwang and H.-M. Wu, "Trajectory tracking of a mobile robot with frictions and uncertainties using hierarchical sliding-mode under-actuated control," IET Control Theory \& Applications, vol. 7, no. 7, pp. 952-965, 2013.

[103] J. Taheri-Kalani and M. J. Khosrowjerdi, "Adaptive trajectory tracking control of wheeled mobile robots with disturbance observer," International Journal of Adaptive Control and Signal Processing, vol. 28, no. 1, pp. 14-27, 2014.

[104] R. Silva-Ortigoza, J. R. García-Sánchez, V. M. HernándezGuzmán, C. Márquez-Sánchez, and M. Marcelino-Aranda, "Trajectory tracking control for a differential drive wheeled mobile robot considering the dynamics related to the actuators and power stage," IEEE Latin America Transactions, vol. 14, no. 2, pp. 657-664, 2016, http://www.ewh.iee.org/reg/ 9/etrans/esp/publicaciones.php.

[105] J. R. García-Sánchez, S. Tavera-Mosqueda, R. Silva-Ortigoza, M. Antonio-Cruz, G. Silva-Ortigoza, and J. de J. Rubio, "Assessment of an average tracking controller that considers all the subsystems involved in a WMR: implementation via PWM or sigma-delta modulation," IEEE Latin America Transactions, vol. 14, no. 3, pp. 1093-1102, 2016.

[106] E. Montané, P. Miribel-Català, J. López-Sánchez, M. Puig-Vidal, S. Bota, and J. Samitier, "High-voltage smart power integrated circuits to drive piezoceramic actuators for microrobotic applications," IEE Proceedings - Circuits, Devices and Systems, vol. 148, no. 6, pp. 343-347, 2001.

[107] M. Karpelson, G.-Y. Wei, and R. J. Wood, "A review of actuation and power electronics options for flapping-wing robotic insects," in Proceedings of the 2008 IEEE International Conference on Robotics and Automation, ICRA 2008, pp. 779786, Pasadena, CA, USA, 2008.

[108] M. G. Tina, C. Ventura, P. Arena, L. Patané, D. A. Grasso, and M. Pollino, "Design considerations about a photovoltaic power system to supply a mobile robot," in Proceedings of the 2010 IEEE International Symposium on Industrial Electronics, ISIE 2010, pp. 1829-1834, Bari, Italy, 2010.

[109] M. Karpelson, J. P. Whitney, G.-Y. Wei, and R. J. Wood, “Design and fabrication of ultralight high-voltage power circuits for flapping-wing robotic insects," in Proceedings of the 26th Annual IEEE Applied Power Electronics Conference and Exposition, APEC 2011, pp. 2070-2077, Fort Worth, TX, USA, 2011.

[110] A. Azidehak, M. Hoshyari, and M. Ahmad Sharbafi, "Design and implementation of minimal components brushless DC motor driver for mobile robots," in Proceedings of the 2011 IEEE
International Conference on Mechatronics, ICM 2011, pp. 642647, Istanbul, Turkey, 2011.

[111] M. Karpelson, G.-Y. Wei, and R. J. Wood, "Driving high voltage piezoelectric actuators in microrobotic applications," Sensors and Actuators A: Physical, vol. 176, pp. 78-89, 2012.

[112] C. Chen, Y. Tang, H. Wang, and Y. Wang, "A review of fabrication options and power electronics for flapping-wing robotic insects," International Journal of Advanced Robotic Systems, vol. 10, no. 3, pp. 1-12, 2013.

[113] Y. Tang, C. Chen, A. Khaligh, I. Penskiy, and S. Bergbreiter, "An ultracompact dual-stage converter for driving electrostatic actuators in mobile microrobots," IEEE Transactions on Power Electronics, vol. 29, no. 6, pp. 2991-3000, 2014.

[114] Y. Tang and A. Khaligh, "Bidirectional resonant DC-DC stepup converters for driving high-voltage actuators in mobile microrobots," IEEE Transactions on Power Electronics, vol. 31, no. 1, pp. 340-352, 2016.

[115] A. W. Divelbiss and J. T. Wen, "Trajectory tracking control of a car-trailer system," IEEE Transactions on Control Systems Technology, vol. 5, no. 3, pp. 269-278, 1997.

[116] R. Silva-Ortigoza, C. Márquez-Sánchez, F. Carrizosa-Corral, M. Antonio-Cruz, J. M. Alba-Martínez, and G. Saldaña-González, "Hierarchical velocity control based on differential flatness for a DC/DC Buck converter-DC motor system," Mathematical Problems in Engineering, vol. 2014, Article ID 912815, 12 pages, 2014.

[117] R. Silva-Ortigoza, V. Hernández-Guzmán, M. Antonio-Cruz, and D. Muñoz-Carrillo, "DC/DC Buck power converter as a smooth starter for a DC motor based on a hierarchical control," IEEE Transactions on Power Electronics, vol. 30, no. 2, pp. 10761084, 2015.

[118] H. Sira-Ramírez and R. Silva-Ortigoza, Control Design Techniques in Power Electronics Devices, Springer-Verlag, London, UK, 2006.

[119] H. Sira-Ramírez and S. K. Agrawal, Differentially Flat Systems, Marcel Dekker, New York, NY, USA, 2004.

[120] R. Toukhtarian, A. Sanjab, and S. Saab, "On the model order reduction of a direct current motor," International Journal of Electrical Engineering Education, vol. 52, no. 1, pp. 52-70, 2015.

[121] M. Fliess, H. Sira-Ramírez, and R. Marquez, "Regulation of nonminimum phase outputs: a flatness based approach," in Perspectives in Control, D. Normand-Cyrot, Ed., SpringerVerlag, London, UK, 1998.

[122] N. Faiz, S. K. Agrawal, and R. M. Murray, "Trajectory planning of differentially flat systems with dynamics and inequalities," Journal of Guidance, Control, and Dynamics, vol. 24, no. 2, pp. 219-227, 2001.

[123] E. Song, A. F. Lynch, and V. Dinavahi, "Experimental validation of nonlinear control for a voltage source converter," IEEE Transactions on Control Systems Technology, vol. 17, no. 5, pp. 1135-1144, 2009.

[124] P. Thounthong and S. Pierfederici, "A new control law based on the differential flatness principle for multiphase interleaved DC-DC converter," IEEE Transactions on Circuits and Systems II: Express Briefs, vol. 57, no. 11, pp. 903-907, 2010.

[125] M. Pahlevaninezhad, P. Das, J. Drobnik, P. K. Jain, and A. Bakhshai, "A new control approach based on the differential flatness theory for an AC/DC converter used in electric vehicles," IEEE Transactions on Power Electronics, vol. 27, no. 4, pp. 2085-2103, 2012. 
[126] C. Márquez-Sánchez, J. R. García-Sánchez, C. Y. SosaCervantes et al., "Trajectory generation for wheeled mobile robots via Bézier polynomials," IEEE Latin America Transactions, vol. 14, no. 11, pp. 4482-4490, 2016.

[127] R. Silva-Ortigoza, J. N. Alba-Juárez, J. R. García-Sánchez, M. Antonio-Cruz, V. M. Hernández-Guzmán, and H. Taud, "Modeling and experimental validation of a bidirectional DC/DC Buck power electronic converter-DC motor system," IEEE Latin America Transactions, vol. 15, no. 6, pp. 1043-1051, 2017.

[128] R. Silva-Ortigoza, J. N. Alba-Juárez, J. R. García-Sánchez, V. M. Hernández-Guzmán, C. Y. Sosa-Cervantes, and H. Taud, "A sensorless passivity-based control for the DC/DC Buck converter-inverter-DC motor system," IEEE Latin America Transactions, vol. 14, no. 10, pp. 4227-4234, 2016.

[129] E. Hernández-Márquez, R. Silva-Ortigoza, J. R. GarcíaSánchez, V. H. García-Rodríguez, and J. N. Alba-Juárez, "A new "DC/DC Buck-Boost converter-DC motor" system: Modeling and experimental validation," IEEE Latin America Transactions, vol. 15, no. 11, pp. 2043-2049, 2017, http://www .ewh.ieee.org/reg/9/etrans/esp/publicaciones.php.

[130] Z. Li, C. Yang, C.-Y. Su, J. Deng, and W. Zhang, "Vision-based model predictive control for steering of a nonholonomic mobile robot," IEEE Transactions on Control Systems Technology, vol. 24, no. 2, pp. 553-564, 2016.

[131] H. Yang, X. Fan, P. Shi, and C. Hua, "Nonlinear control for tracking and obstacle avoidance of a wheeled mobile robot with nonholonomic constraint," IEEE Transactions on Control Systems Technology, vol. 24, no. 2, pp. 741-746, 2016.

[132] R. D. Cruz-Morales, M. Velasco-Villa, R. Castro-Linares, and E. R. Palacios-Hernandez, "Leader-follower formation for nonholonomic mobile robots: Discrete-time approach," International Journal of Advanced Robotic Systems, vol. 13, no. 2, pp. 1-12, 2016.

[133] K. J. Kaliński and M. Mazur, "Optimal control of 2-wheeled mobile robot at energy performance index," Mechanical Systems and Signal Processing, vol. 70-71, pp. 373-386, 2016.

[134] N.-B. Hoang and H.-J. Kang, "Neural network-based adaptive tracking control of mobile robots in the presence of wheel slip and external disturbance force," Neurocomputing, vol. 188, pp. $12-22,2016$.

[135] C.-L. Hwang and W.-L. Fang, "Global fuzzy adaptive hierarchical path tracking control of a mobile robot with experimental validation," IEEE Transactions on Fuzzy Systems, vol. 24, no. 3, pp. 724-740, 2016.

[136] I.-H. Li, Y.-H. Chien, W.-Y. Wang, and Y.-F. Kao, "Hybrid intelligent algorithm for indoor path planning and trajectorytracking control of wheeled mobile robot," International Journal of Fuzzy Systems, vol. 18, no. 4, pp. 595-608, 2016.

[137] E. Vos, A. J. van der Schaft, and J. M. Scherpen, "Formation control and velocity tracking for a group of nonholonomic wheeled robots," IEEE Transactions on Automatic Control, vol. 61, no. 9, pp. 2702-2707, 2016.

[138] Z. Peng, G. Wen, S. Yang, and A. Rahmani, "Distributed consensus-based formation control for nonholonomic wheeled mobile robots using adaptive neural network," Nonlinear Dynamics, vol. 86, no. 1, pp. 605-622, 2016.

[139] K. R. Simba, N. Uchiyama, and S. Sano, "Real-time smooth trajectory generation for nonholonomic mobile robots using Bézier curves," Robotics and Computer-Integrated Manufacturing, vol. 41, pp. 31-42, 2016.

[140] H. Xiao, Z. Li, C. Yang et al., "Robust stabilization of a wheeled mobile robot using model predictive control based on neurodynamics optimization," IEEE Transactions on Industrial Electronics, vol. 64, no. 1, pp. 505-516, 2017.

[141] M. Seder, M. Baotić, and I. Petrović, "Receding horizon control for convergent navigation of a differential drive mobile robot," IEEE Transactions on Control Systems Technology, vol. 25, no. 2, pp. 653-660, 2017.

[142] S. Yang, Y. Cao, Z. Peng, G. Wen, and K. Guo, "Distributed formation control of nonholonomic autonomous vehicle via RBF neural network," Mechanical Systems and Signal Processing, vol. 87, part B, pp. 81-95, 2017.

[143] M. Chen, "Disturbance attenuation tracking control for wheeled mobile robots with skidding and slipping," IEEE Transactions on Industrial Electronics, vol. 64, no. 4, pp. 33593368, 2017.

[144] H. Wang, D. Guo, X. Liang, W. Chen, G. Hu, and K. K. Leang, "Adaptive vision-based leader-follower formation control of mobile robots," IEEE Transactions on Industrial Electronics, vol. 64, no. 4, pp. 2893-2902, 2017.

[145] H. Ashrafiuon, S. Nersesov, and G. Clayton, "Trajectory tracking control of planar underactuated vehicles," IEEE Transactions on Automatic Control, vol. 62, no. 4, pp. 1959-1965, 2017.

[146] K. Y. Lui, H. Cho, C. Ha, and D. Lee, "First-person view semi-autonomous teleoperation of cooperative wheeled mobile robots with visuo-haptic feedback," International Journal of Robotics Research, vol. 36, no. 5-7, pp. 840-860, 2017.

[147] B. Mu, J. Chen, Y. Shi, and Y. Chang, "Design and implementation of nonuniform sampling cooperative control on a group of two-wheeled mobile robots," IEEE Transactions on Industrial Electronics, vol. 64, no. 6, pp. 5035-5044, 2017.

[148] N. Lashkari, M. Biglarbegian, and S. X. Yang, "Development of a new robust controller with velocity estimator for docked mobile robots: theory and experiments," IEEE/ASME Transactions on Mechatronics, vol. 22, no. 3, pp. 1287-1298, 2017.

[149] C.-H. Sun, Y.-J. Chen, Y.-T. Wang, and S.-K. Huang, "Sequentially switched fuzzy-model-based control for wheeled mobile robot with visual odometry," Applied Mathematical Modelling: Simulation and Computation for Engineering and Environmental Systems, vol. 47, pp. 765-776, 2017.

[150] B. S. Park and S. J. Yoo, "A low-complexity tracker design for uncertain nonholonomic wheeled mobile robots with timevarying input delay at nonlinear dynamic level," Nonlinear Dynamics, vol. 89, no. 3, pp. 1705-1717, 2017. 


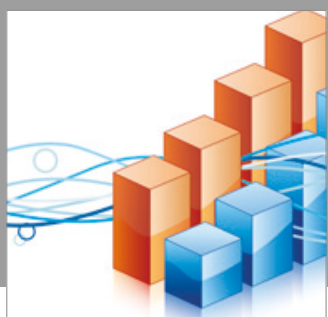

Advances in

Operations Research

vatersals

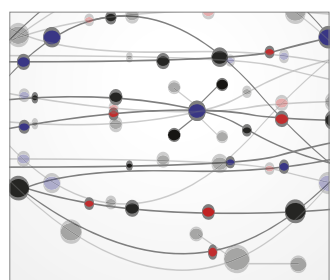

\section{The Scientific} World Journal
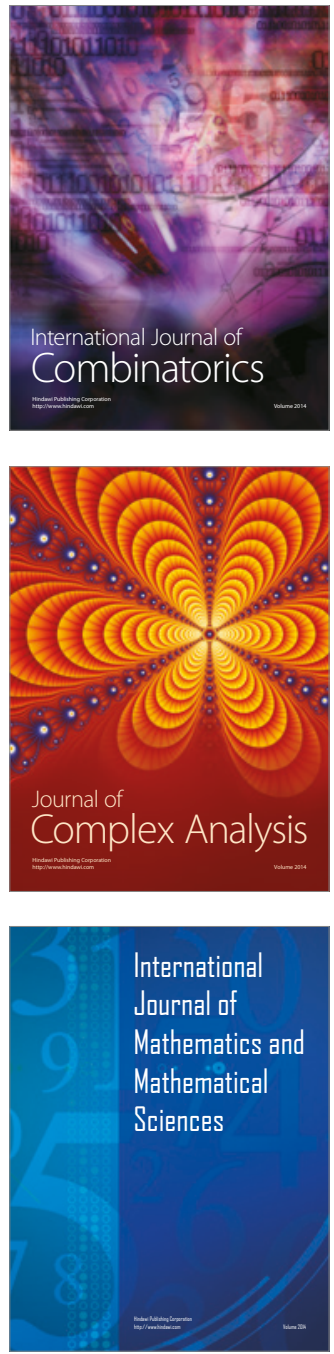
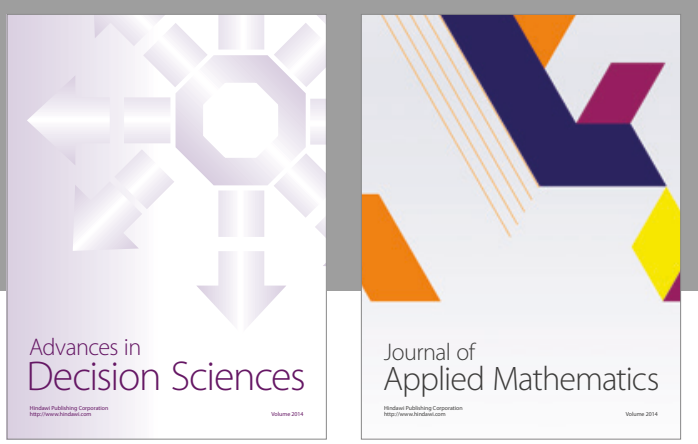

Algebra

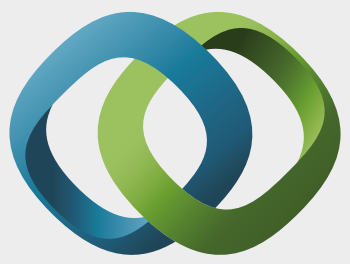

\section{Hindawi}

Submit your manuscripts at

https://www.hindawi.com
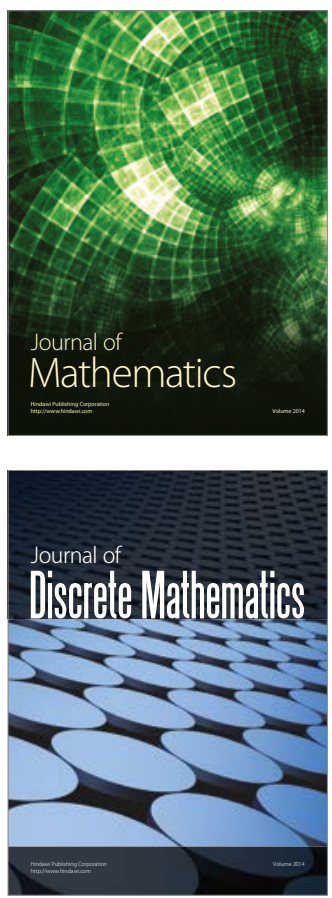

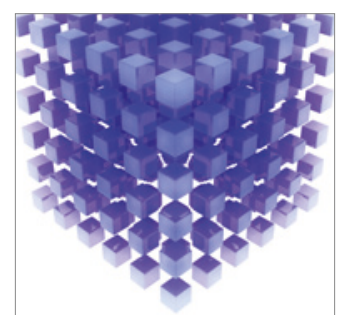

Mathematical Problems in Engineering
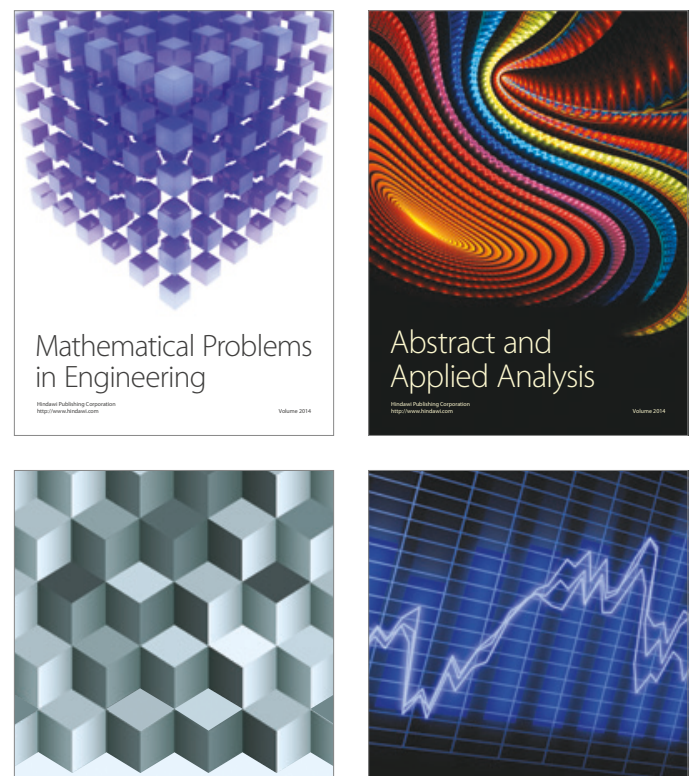

Journal of

Function Spaces

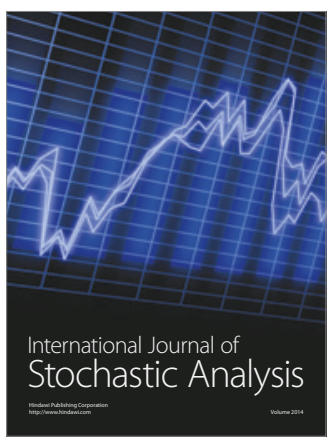

Probability and Statistics
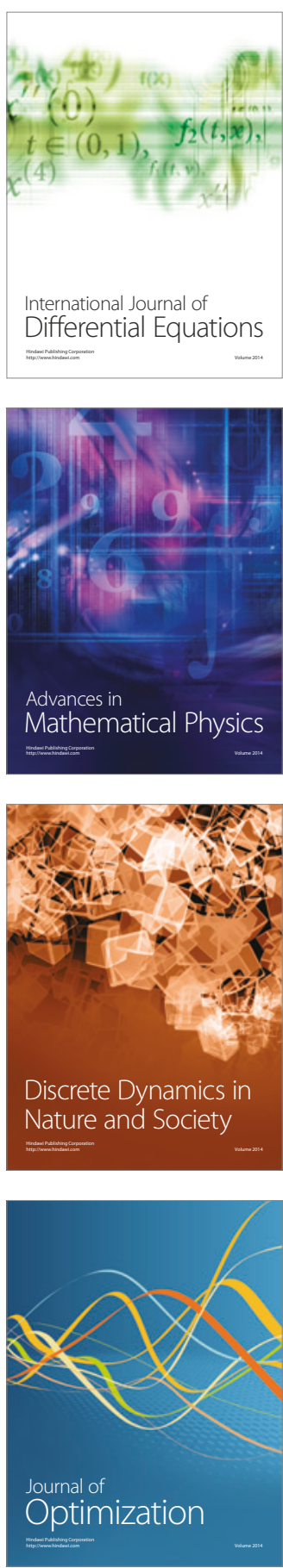